\title{
É POSSÍVEL UMA FUNDAMENTAÇÃO DO DIREITO NEUTRA MORALMENTE? QUATRO MODELOS ANALISADOS POR HABERMAS*
}

\author{
Delamar Dutra
}

\author{
Universidade Federal de Santa Catarina
}

\begin{abstract}
Resumo: O texto visa a apresentar, de modo mais sistemático, a crítica que Habermas endereça a quatro autores fundamentais da filosofia do direito: Hobbes, Kant, Weber e Rawls. $O$ estudo se concentra em demonstrar como Habermas entende o papel da moral na argumentação de cada um deles, tendo em vista a fundamentação do direito.
\end{abstract}

Palavras-chave: Habermas; Hobbes; Kant; Weber; Rawls; moral e direito; fundamentação.

\begin{abstract}
The text aims to present, in a more systematic way, the criticism that Habermas addresses to four fundamental authors of the philosophy of law: Hobbes, Kant, Weber and Rawls. The study focuses on demonstrating how Habermas understands the role of morals in each one's argumentation, in view of the rationale of law.
\end{abstract}

Keywords: Habermas; Hobbes; Kant; Weber; Rawls; morals and Law; foundation.

\section{Introdução}

Habermas analisa pelo menos quatro modelos de fundamentação do direito: o de Hobbes, o de Kant, o de Weber e o de Rawls. Na maior parte dos casos, a análise é crítica e feita de maneira rápida, sem um maior cuidado em ofertar evidências textuais para tal. Mesmo assim, as suas teses interpretativas não deixam de ter importância para serem estudadas, ainda que demandem um esforço maior de compreensão.

\footnotetext{
* Abreviaturas: As referências a Kant seguem a uniformização proposta pela Kant-Studien Redaktion, disponíveis em http://www.kant.uni-mainz.de/ks/abhandlungen.html As citações literais são feitas a partir das traduções para o vernáculo das referidas obras.

\begin{tabular}{|l|l|}
\hline FG & $\begin{array}{l}\text { HABERMAS, J. Faktizität und Geltung: Beiträge zur Diskurstheorie des Rechts und des } \\
\text { demokratischen Rechtsstaats. 4. Auflage, Frankfurt am Main: Suhrkamp, 1994. }\end{array}$ \\
\hline TrFG1 & $\begin{array}{l}\text { HABERMAS, J. Direito e democracia: entre faticidade e validade. [v. I]. [Trad. F. B. } \\
\text { Siebeneichler: Faktizität und Geltung: Beiträge zur Diskurstheorie des Rechts und des } \\
\text { demokratischen Rechtsstaats]. Rio de Janeiro: Tempo Brasileiro, 1997. }\end{array}$ \\
\hline TrFG2 & $\begin{array}{l}\text { HABERMAS, J. Direito e democracia: entre faticidade e validade. [v. II]. [Trad. F. B. } \\
\text { Siebeneichler: Faktizität und Geltung: Beiträge zur Diskurstheorie des Rechts und des } \\
\text { demokratischen Rechtsstaats]. Rio de Janeiro: Tempo Brasileiro, 1997. }\end{array}$ \\
\hline
\end{tabular}
}


Os autores citados são analisados por Habermas em momentos distintos de sua obra e as análises são sempre feitas no interesse construtivo de sua própria teoria discursiva do direito. Portanto, o seu objetivo não é, nem de longe, analisar as teorias que cita, mas sim apresentá-las como modelos em relação aos quais o seu próprio projeto será colocado em melhor luz.

Nesse sentido, um dos pontos fundamentais do projeto de Habermas é realizado em Direito e democracia, qual seja, aquele da relação complementar entre direito e moral. Esse texto é exemplar do modo como Habermas usa a história da filosofia para as finalidades de seu próprio projeto. Especificamente, neste texto, e, especificamente, no que concerne à relação entre direito e moral, dois autores são importantes para sua análise, Hobbes e Kant. Na interpretação que Habermas oferta de Hobbes, ele é analisado como um mecanicista que busca estatuir as normas jurídicas a partir de um raciocínio estratégico, no qual não deveriam se imiscuir argumentos morais. Contudo, sustenta Habermas, os argumentos morais operariam de forma velada no próprio raciocínio de Hobbes, a saber, no uso que ele faz da regra de ouro. A regra de ouro traria para a filosofia de Hobbes o tipo de argumento moral que sua posição inicial pareceria excluir. Kant, por outro lado, teria percebido a insuficiência da posição de Hobbes e teria operado com uma argumentação moral explícita.

Habermas pretende estatuir a sua teoria discursiva do direito evitando os problemas de ambas as posições. Nesse sentido, Hobbes seria insuficiente por ter excluído os argumentos normativos necessários para que seu sistema pudesse ser concebido. Ou seja, a teoria de Hobbes usaria, na verdade, argumentos morais implícitos, mostrando, com isso, a impossibilidade de uma argumentação estritamente estratégica. Kant, por seu turno, teria exagerado no uso dos argumentos normativos, dando-lhes um estatuto moral. Nesse diapasão, Direito e democracia sustenta uma posição intermediária entre a teoria instrumental de Hobbes e a teoria moral de Kant. A sua própria teoria discursiva seria portadora de normatividade, contudo, não em um sentido moral.

Outros dois modelos são analisados em contextos diferentes. O modelo de Weber foi tratado nas Tanner Lectures' e o modelo de Rawls no

10 texto que ficou conhecido por este nome resultou de algumas conferências proferidas por Habermas em 1986, em Harvard, sendo primeiramente publicado com o título Law and Morality em 1988 no volume VIII da coleção The Tanner Lectures on Human Values, organizada por McMURRIN, S. M., traduzida por $\mathrm{K}$. Baynes. $\mathrm{O}$ original Habermas publicou nos estudos preliminares e complementares a Faktizität und Geltung, com o título Recht und Moral (Tanner Lectures 1986). Por essa razão, utiliza-se a tradução portuguesa de Siebeneichler, com a paginação da publicação em "Direito e Democracia". 
contexto do debate ${ }^{2}$ travado entre os dois em 1995. Os modelos serão apresentados na ordem histórica em que o tratamento dos mesmos ocorreu na obra de Habermas.

\section{O modelo de Weber}

Segundo Weber, a legitimidade é uma crença no dever-ser de uma norma ${ }^{3}$. No caso do direito, como ordem jurídica, ele está garantido externamente pela probabilidade da coação (física ou psíquica) ${ }^{4}$, já que a legalidade é uma forma de legitimidade sobre a qual se acrescenta a coerção, o que permite que ela seja classificada como possível de ser legitimada com relação a fins.

O conceito de coerção remete ao conceito de poder, cuja definição ele apresenta do seguinte modo: "poder (Macht) significa a probabilidade de impor a própria vontade, dentro de uma relação social, mesmo contra toda a resistência e qualquer que seja o fundamento desta probabilidade" ${ }^{5}$. O poder, quando revestido de legitimidade, é obedecido. A obediência aos ditames do poder metamorfoseia-o em dominação, sendo a disciplina uma obediência automatizada. Uma associação de dominação é politica quando pode contar com a coerção externa, portanto, com o poder. O Estado é um instituto político que consegue manter com êxito o monopólio legítimo do uso da força física para sustentar a ordem, a qual, ainda que não seja o modo normal de manutenção das associações políticas, é o seu meio específico, a sua última ratio.

Essa consideração de Weber, por um lado, unifica poder e direito, enquanto uma pura forma coercitiva despida de conteúdo e, por outro lado, separa essa forma de qualquer conteúdo que lhe possa ser acrescentado. Ou seja, a definição de direito, como acima visto, une-o, intrinsecamente, com o poder, ou seja, com a coerção, despojando-o de qualquer conteúdo. Mesmo a legitimidade jurídica, aqui, é privada de conteúdo, pois ela é formal, remetendo

2 (A) $O$ primeiro texto do debate, suscitado a pedido do The Journal of Philosophy, é: HABERMAS, J. "Reconciliation through the Public Use o Reason: Remarks on John Rawl's Political Liberalism". In: The Journal of Philosophy, v.92, n.3, p.109-31, March 1995. (B) A resposta de Rawls está publicada no mesmo volume: RAWLS, J. "Reply to Habermas". In: The Journal of Philosophy, v.92, n.3, March 1995, p.132-180. (C) A tréplica de Habermas se deu com o texto: "Reasonable" versus "True" or the Morality of Worldviews. Este texto está publico como o cap. 3 do livro HABERMAS, J. The Inclusion of the Other: Studies in Political Theory. [Transl. Ciaran Cronin: Die Einbeziehung desanderen Studien zur politischen Theorie]. Cambridge: MIT Press, 1998 [1996].

3 WEBER, M. Wirtschaft und Gesellschaft. Tübingen: Mohr, s/d, p.16.

${ }^{4}$ Idem, ibidem, p.17.

5 Idem, ibidem, p.28. 
ao procedimento de sua criação e à crença de que esse procedimento é legítimo. Nas palavras de Weber,

não é possível definir uma associação política - inclusive o "Estado" assinalando os fins da "ação da associação" [...] não existiu nenhum fim que ocasionalmente não haja sido perseguido pelas associações políticas; e não houve nenhum [...] que todas essas associações tenham perseguido. Só se pode definir, por isso, o caráter político de uma associação pelo meio [...] que sem ser-lhe exclusivo é certamente específico e para a sua essência indispensável: a coação física $^{6}$.

Portanto, não há, para ele, um direito substancial que possa receber o nome de direito, independentemente de um aparato normativo. Daí se poder filiá-lo ao positivismo, pois este se caracteriza menos pela afirmação de que o direito é o direito positivo e mais pelo que subjaz a essa afirmação, a saber, que o direito é o direito positivo porque, em última análise, ele não passa de uma forma coercitiva ${ }^{7}$. A formulação de Kelsen sobre o direito positivo ajuda a compreender melhor a posição de Weber:

[...] o Direito positivo é essencialmente uma ordem de coerção. Ao contrário das regras do direito natural, as suas regras derivam da vontade arbitrária de uma autoridade humana e, por esse motivo, simplesmente por causa da natureza de sua fonte, elas não podem ter a qualidade da auto-evidência imediata. $O$ conteúdo das regras do Direito positivo carece da necessidade "interna" que é peculiar às regras do direito natural em virtude de sua origem [...] a doutrina que declara a coerção como característica essencial do Direito é uma doutrina positivista e se ocupa unicamente com o Direito positivo $^{8}$.

Para Kelsen, consequentemente, o sistema do direito natural tende a ser um sistema estático, o que determina um caráter conservador do mesmo, ao contrário do direito positivo que é um sistema dinâmico em razão de se reconhecer como um produto da atividade humana. Aliás, a afirmação de Direito e democracia de que a forma jurídica não é fundamentada moralmente9 honra a seu modo essa formulação positivista do direito.

Tal consideração permite a Weber oferecer uma concepção de legitimidade da legalidade de caráter formal ${ }^{10}$, isto é, neutra com relação a conteúdos, bem como uma concepção de direito que corresponde a essa neutralidade. Nesse sentido, Weber é partidário de uma legitimidade estritamente processual, já que uma norma portará um índice de crença na sua legitimidade pelo motivo principal do procedimento legal pelo qual passou: "a

\footnotetext{
${ }^{6}$ WEBER, M. Wirtschaft und Gesellschaft. Tübingen: Mohr, s/d, p.30.

${ }^{7}$ FG p.113.

${ }^{8}$ KELSEN, H. Teoria geral do direito e do Estado. São Paulo: Martins Fontes, 2000, p.559.

${ }^{9}$ FG p.143.

10 WEBER, M. Wirtschaft und Gesellschaft. Tübingen: Mohr, s/d, p.502s.
} 
forma de legitimidade hoje mais corrente é a crença na legalidade: a obediência a preceitos jurídicos positivos estatuídos segundo o procedimento usual e formalmente correto"11. Dessa forma, segundo ele, o que caracteriza a dominação legal é que "qualquer direito pode ser criado e modificado mediante um estatuto sancionado corretamente quanto à forma" 12 . Sendo a legitimidade uma crença, nada impede que normas distintas e mesmo contraditórias possam ser consideradas como válidas ${ }^{13}$. Sendo assim, pode-se ver como Weber apresenta um conceito de direito, bem como de poder, neutro com relação a qualquer determinação de legitimidade no que concerne a conteúdos, já que qualquer conteúdo pode ser objeto de uma norma legítima.

Esse imbricamento entre Estado e legalidade remete à noção de Estado legal, cuja melhor formulação para Weber será a burocracia. O Estado regido pela legalidade é portador de algumas características peculiares. Primeiro, o seu aspecto processual, já que qualquer direito pode ser criado e modificado por meio de um estatuto sancionado corretamente quanto à forma, como visto acima. Em segundo lugar, a legalidade, já que se obedece não à pessoa em virtude de seu direito próprio, mas à regra estatuída, a qual estabelece, ao mesmo tempo, a quem e em que medida se deve obedecer, de tal forma que também o que emite uma ordem obedece a uma regra, a saber, à lei ou ao regramento de uma norma formalmente abstrata ${ }^{14}$.

Contrariando as teses de Weber expostas na Teoria da ação comunicativa de 1981, Habermas vincula, em parte do texto, a legitimidade do direito à racionalidade moral, esta última apresentada nas Notas programáticas para uma fundamentação da ética discursiva ${ }^{15}$ de 1983 , sendo tal vinculação desenvolvida sistematicamente nas Tanner Lectures de 1986, e em Wie ist Legitimität durch Legalität möglich? de 1987.

No mencionado texto de 1981, Teoria da ação comunicativa, Habermas parte da análise de três características imputadas por Weber ao direito, mormente o moderno, a positividade, a legalidade e a formalidade ${ }^{16}$. Chama a atenção, particularmente com relação ao primeiro ponto, o caráter póstradicional do direito, ou seja, a vinculação do direito àquele estatuto positivado pelo legislador. Já com relação ao segundo aspecto, destaca-se a

\footnotetext{
11 Idem, ibidem, p.19.

12 WEBER, M. Os três tipos puros de dominação legítima. (Coleção grandes cientistas sociais n.13. WEBER, M. Sociologia). 5. ed., São Paulo: Ática, 1991, p.128.

13 WEBER, M. Wirtschaft und Gesellschaft. Tübingen: Mohr, s/d, p.16s.

14 WEBER, M. Os três tipos puros de dominação legítima. (Coleção grandes cientistas sociais n.13. WEBER, M. Sociologia). 5. ed., São Paulo: Ática, 1991, p.129.

15 Trata-se do cap. 3 de Consciência moral e agir comunicativo.

${ }^{16}$ HABERMAS, J. Theorie des kommunikativen Handelns. (Band I). Frankfurt am Main: Suhrkamp, 1981, p.351s.
} 
independência dos motivos e, portanto, uma versão processual da legitimidade e, com relação ao último, estatui-se a neutralização moral do direito.

Com o conceito de fé na legalidade, Weber estabelece um vínculo com a racionalidade que habita na forma do direito - o que legitima o poder exercido segundo tal forma - desvinculando a legitimidade da fé na tradição ou no carisma. "Isso significa, para Weber, que o direito dispõe de uma racionalidade própria, que não depende da moral"17. Ao contrário, qualquer ligação com a moral implicaria um risco a essa racionalidade. Como ver-se-á, o que Habermas procurará no contexto das Tanner Lectures será negar esta tese, a saber, que a racionalidade da forma jurídica seja independente da moral, ao passo que em Direito e democracia ele restabelecerá - em termos - a tese de Weber, sem, no entanto, despedir a moral tout court.

Essa neutralização moral do direito em conjunção com uma concepção decisionista do mesmo, como dito, é a questão que Habermas quer criticar. O ponto está em que, sendo controversos os princípios substantivos de moralidade, como natureza e razão, Weber - na interpretação de Habermas - une uma concepção positivista de procedimento $^{18}$ que engendra a legitimidade com um conceito decisionista ${ }^{19}$ dos conteúdos.

Nesse particular cabe um esclarecimento sobre o que significa ser positivista e decisionista. Habermas define o decisionismo como um ato discricionário $^{20}$ ou como aquele que decide sem fundamentos ${ }^{21}$. Já o positivismo, para ele, é aquela posição que privilegia a segurança sobre a correção ${ }^{22}$. Fazendo uso da terminologia introduzida por Dworkin que distingue princípios de regras, o positivista é o que nega tal distinção, tendo por consequência a redução de todas as normas jurídicas a regras, o que determina, em não havendo princípios, que se tenha que decidir discricionariamente no caso de lacuna das regras. Nesse caso, o positivista é um decisionista ${ }^{23}$. Habermas, por seu turno, quer evitar ambos, ou seja, um

\footnotetext{
17 TrFG2 p.193 [FG p.541].

${ }^{18}$ HABERMAS, J. Theorie des kommunikativen Handelns. (Band I). Frankfurt am Main: Suhrkamp, 1981, p.358s.

19 Idem, ibidem, p.361s.

20 FG p.248.

21 HABERMAS, J. Theorie des kommunikativen Handelns. (Band I). Frankfurt am Main: Suhrkamp, 1981, p.358s.

22 FG p.248.

${ }^{23} \mathrm{FG}$ p.256. 0 positivismo responde a um aspecto conceitual da teoria do direito, segundo o qual "a verdade de uma proposição legal consiste em fatos acerca das regras que foram adotadas por instituições sociais específicas e nada mais que isto" (DWORKIN, R. Taking Rights Seriously. London: Duckworth, 1977, p.VII). Portanto, dentre outras consequências, não existem direitos anteriores ao direito positivo. Calcado no princípio da segurança, o positivismo determina o encurtamento semântico das normas, operando, tecnicamente, com o conceito de regras, as quais têm uma abrangência
} 
conceito positivista de procedimento, bem como uma concepção decisionista dos conteúdos.

No sentido apontado acima, a argumentação de Habermas consiste em mostrar como em Weber já opera implicitamente um tipo de racionalidade para além daquela instrumental por ele explicitamente admitida, a qual estaria na base da própria justificação da legalidade. Aliás, como já mencionado, ele usa uma argumentação semelhante contra Hobbes. Ele analisa dois pontos centrais da teoria weberiana nos quais isso ocorreria. $\mathrm{O}$ primeiro se refere à definição de ação social e o segundo à definição de legitimidade do direito. Em ambos os momentos, Habermas quer flagrar a racionalidade comunicativa operando implicitamente na argumentação weberiana.

Com relação ao primeiro ponto, de fato, Weber define "ação" do seguinte modo: "por 'ação' se deve entender uma conduta humana [...] sempre que o sujeito ou sujeitos da ação unam a ela um sentido subjetivo"24. O ponto de Habermas é que ele, para introduzir o conceito de ação social, não pode fazê-lo somente com a definição acima que Habermas avalia em sua terminologia como monológica e intencionalista, portanto, devedora do paradigma da consciência, o qual implica certo grau de solipsismo. Por isso, Weber tem que fazer duas determinações a mais que extrapolariam o limite de sua definição, determinações essas que poriam em operação elementos de uma racionalidade comunicativa obliterada no texto explícito. Nesse sentido, veja-se agora a definição de ação social: “a 'ação social', portanto, é uma ação na qual o sentido mentalizado por um sujeito ou sujeitos está referido à conduta de outros, orientando-se por esta em seu desenvolvimento"25. Ou seja, a ação social se orienta pelas ações dos outros ${ }^{26}$. Além disso, ele acrescenta: "por 'relação' social se deve entender uma conduta plural - de vários - que, pelo sentido que encerra, se apresenta como reciprocamente 'referida', orientandose por essa reciprocidade" 27 . Assim, ele não consegue introduzir o conceito de ação social como uma explicação do conceito de sentido subjetivo tal qual declinado na definição básica de ação, mas se vê na necessidade de completar o modelo da ação teleológica com duas determinações a mais para que se

semântica bem determinada: "Rules are applicable in an all-or-nothing fashion"; princípios têm "the dimension of weight or importance" (DWORKIN, R. Taking Rights Seriously. London: Duckworth, 1977, p.24 e p.26). Assim, o positivismo apresenta um tipo de aplicação mecânica para os casos simples e, para os casos difíceis, uma aplicação baseada na discricionariedade (discretion), sendo que onde há arbítrio do juiz não há lei: "So far as the judge's arbitrium extends, there is no law at all" (AUSTIN, J. Lectures on Jurisprudence. (V. I). Glashütten im Taunus: Auvermann, 1972. (1.ed., 1863. p.664).

${ }^{24}$ WEBER, M. Wirtschaft und Gesellschaft. Tübingen: Mohr, s/d, p.1.

25 Idem, ibidem, p.1.

${ }^{26}$ Idem, ibidem, p.11.

${ }^{27}$ WEBER, M. Wirtschaft und Gesellschaft. Tübingen: Mohr, s/d, p.13. 
possam cumprir as condições para definir uma ação como social, a saber, (a) a orientação em função do comportamento dos outros e (b) a relação reflexiva entre as orientações para ação, ou seja, deverão ser ações reciprocamente referidas $^{28}$.

No caso do direito, Weber define a legitimidade da legalidade do seguinte modo: "esta legalidade pode valer como legítima: (a) em virtude de um pacto dos interessados; (b) em virtude de uma imposição (Oktroyierung) por uma autoridade (Herrschaft) considerada legítima e da correspondente obediência"29. Em qualquer uma dessas formulações, a fonte da legitimidade não é a legalidade enquanto tal - acusa Habermas -, mas, no primeiro caso, um acordo, um pacto e, no segundo, uma autoridade já considerada legítima. Como se sabe, os dois critérios se mesclam, pois nunca um pacto é unânime, sendo as regras da maioria impostas à minoria pela autoridade legítima resultante da maioria. De qualquer modo, a fonte de legitimidade não é a legalidade como tal, mas o acordo. Aponta-se, assim, para a insuficiência do critério formal legal de correção do direito, buscando uma fundamentação de outro tipo, de tal modo que "a fé na legalidade de um procedimento não pode engendrar per se legitimidade, isto é, somente pela virtude da correção processual do procedimento estabelecido positivamente" 30 .

Interessantemente, no contexto das Tanner Lectures, Habermas defende - contra Weber - a tese de que a legitimidade não resulta das características formais do direito, a saber, (a) do seu caráter sistemático; (b) do seu caráter abstrato e geral e (c) da segurança ${ }^{31}$ e, sim, "de implicações morais, que podem ser inferidas dessas características" "32. No texto, ele faz uma minuciosa análise dos caracteres do direito que Weber considerara formais, para desmascará-los na sua natureza verdadeiramente moral. Uma acusação, aliás, que Rawls parece endereçar ao Habermas de Direito e democracia ${ }^{33}$.

\footnotetext{
${ }^{28}$ HABERMAS, J. Theorie des kommunikativen Handelns. (Band I). Frankfurt am Main: Suhrkamp, 1981, p.378.

29 WEBER, M. Wirtschaft und Gesellschaft. Tübingen: Mohr, s/d, p.19.

${ }^{30}$ HABERMAS, J. Theorie des kommunikativen Handelns. (Band I). Frankfurt am Main: Suhrkamp, 1981, p.360.

31 WEBER, M. Wirtschaft und Gesellschaft. Tübingen: Mohr, s/d, p.504.

32 HABERMAS, J. Direito e democracia: entre faticidade e validade. (v. II). Rio de Janeiro: Tempo Brasileiro, 1997, p.198 [HABERMAS, J. Faktizität und Geltung: Beiträge zur Diskurstheorie des Rechts und des demokratischen Rechtsstaats. 4. Auflage, Frankfurt am Main: Suhrkamp, 1994, p.547].

33 "I see my reply as a defense of liberalism since any liberal view must be substantive, and it is correct in being so. Moreover, I do not see why Habermas's view is not also substantive, even though the substantive elements may differ" (RAWLS, J. Political Liberalism. New York: Columbia University Press, 1996, p.421). Por "substância" Rawls entende no presente contexto, valores morais como a imparcialidade, como se verá adiante.
} 
Portanto, as qualidades formais do direito só poderiam garantir a legitimidade "na medida em que se tivessem comprovado como 'racionais' em um sentido prático moral" 34 . Habermas acusa Weber de não ter reconhecido isso devido ao seu ceticismo moral, o qual militava contra uma moral substantiva que fosse válida universalmente. No entanto, avalia Habermas, ele não levou a sério a possibilidade de uma moral cognitivista, embora formalmente considerada. Dito claramente, nas Tanner Lectures, "a legitimidade da legalidade não pode ser explicada a partir de uma racionalidade autônoma inserida na forma jurídica isenta de moral; ela resulta, ao invés disso, de uma relação interna entre direito e moral" 35 . Ele propõe mesmo uma fusão, um entrelaçamento (Verschränkung) de procedimentos: "a legitimidade pode ser obtida através da legalidade na medida em que os processos para a produção de normas jurídicas são racionais no sentido de uma razão prático-moral procedimental. A legitimidade da legalidade resulta do entrelaçamento entre processos jurídicos e uma argumentação moral que obedece à própria racionalidade procedimental" 36 .

Nas Tanner Lectures, como já mencionado, Habermas levanta as seguintes características formais que Weber imputa ao direito: (a) o caráter sistemático; (b) o caráter abstrato e geral; (c) a segurança ${ }^{37}$. Desse modo, como já propusera Weber, e conforme já foi mencionado acima, pode-se concluir facilmente que "a racionalidade do direito está fundamentada nas suas qualidades formais" 38 , o que implica a tese da sua neutralidade sob o ponto de vista moral. Tal ocorre porque "a materialização configura uma moralização do direito, isto é, a introdução de pontos de vista da justiça material no direito positivo. Disso resultou a afirmação crítica, segundo a qual, o estabelecimento de um nexo interno entre direito e moral destrói a racionalidade que habita no medium do direito enquanto tal" 39 .

34 HABERMAS, J. Direito e democracia: entre faticidade e validade. (v. II). Rio de Janeiro: Tempo Brasileiro, 1997, p.200-1 [HABERMAS, J. Faktizität und Geltung: Beiträge zur Diskurstheorie des Rechts und des demokratischen Rechtsstaats. 4. Auflage, Frankfurt am Main: Suhrkamp, 1994, p.549].

35 Idem, ibidem, p.550.

36 Idem, ibidem, p.552.

37 WEBER, M. Wirtschaft und Gesellschaft. Tübingen: Mohr, s/d, p.504.

38 TrFG2 p.197 [FG p.545].

39 TrFG2 p.197 [FG p.547]. O próprio Weber constata como o direito natural formal, por exemplo aquele do modelo contratualista, se transformou progressivamente em direito natural substantivo, a partir de determinações sociais e econômicas, como é o caso do socialismo ou das posições regulamentadoras e limitadoras da vontade contratual negocial. Tal é o caso da tese da exploração do Estado de necessidade na lei da usura, a qual proíbe juros elevados, e a nulidade das cláusulas contratuais leoninas (WEBER, M. Wirtschaft und Gesellschaft. Tübingen: Mohr, s/d, p.506). Tais limitações ao formalismo só podem ser feitas, segundo ele, a partir de determinações materiais, ligadas, não ao 
É desse modo que, no que concerne a (c), a segurança jurídica, podese perceber que ela é na verdade um valor dentre outros e que concorre com outros valores, por exemplo, com a participação em igualdade de chances no processo político e com a justiça social, até porque, neste último caso, as leis são feitas com conceitos jurídicos indeterminados, como os de saúde e de educação. Ou seja, às vezes, oblitera-se discretamente razões de segurança jurídica em nome de uma maior legitimidade ${ }^{40}$. No entanto, esses são valores concorrentes que têm que ser sopesados e decididos: "tais colisões têm que ser decididas sob o ponto de vista moral da possibilidade de universalização de interesses" ${ }^{41}$. Com relação a (b), o caráter abstrato e geral, percebe-se a sua aproximação ao princípio da igualdade perante a lei, o que corresponde ao princípio: "aquilo que é igual tem que ser tratado de modo igual e o que é diferente tem que ser tratado de modo diferente" 42 . Por fim, (a), o caráter sistemático é só um elemento na busca de fundamentação, a qual se torna mais premente em razão da modificabilidade do direito. Assim, o trabalho sistematizador visaria a encontrar princípios evidentes que justificariam o direito, mesmo este sendo modificável. Este caráter principiológico da sistematização aponta para uma validade pós-tradicional que não poderia se basear só nos costumes. No entanto, os princípios gerais uma vez encontrados, quando problematizados, clamariam mais, para sua fundamentação, a uma razão prática no sentido de Kant, do que a uma racionalidade científica neutra moralmente que se limitaria a encontrar e a formular claramente tais princípios já operantes ${ }^{43}$.

Como se percebe, a argumentação contra Weber aponta no sentido de moralizar o procedimento jurídico, a partir da ética discursiva, a qual se autocompreende em um sentido formal. Assim, Habermas, na medida em que aceita parcialmente o ceticismo de Weber quanto à moral tradicional, reconstrói, também, a possibilidade de uma moral racional em um nível mais abstrato, aquele dos procedimentos, "porque a força legitimadora reside em processos que institucionalizam o caminho para o seu resgate argumentativo" 44 . Assim, o que a filosofia - ausente em Weber, como mencionado - pode justificar é um procedimento que marcará os seus produtos com a

mundo jurídico, mas ao mundo ético, o qual, como sabemos, porta, para Weber, uma certa dose de irracionalidade por remeter sempre a uma moral tradicional.

40 Veja-se a esse respeito THEODORO JÚNIOR, H. e FARIA, J. C. de. "A coisa julgada inconstitucional e os instrumentos processuais para seu controle". In: Revista dos tribunais. São Paulo. Ano 91, v.795, p.21-40, jan de 2002.

41 TrFG2 p.199 [FG p.547].

42 TrFG2 p.200 [FG p.548].

43 TrFG2 p.200 [FG p.548-9].

${ }^{44}$ TrFG2 p.214 [FG p.563]. 
legitimidade, embora não haja garantias de que isso ocorra, devido às limitações a que tais procedimentos estão submetidos.

Cabe observar que o caminho da remoralização do direito escolhido por Habermas busca evitar o que poderia se assemelhar a uma renovação do direito natural, pois este, frente a uma sociedade pluralista, teria conteúdos com premissas normativas fortes demais, de tal sorte que "somente as teorias da justiça e da moral ancoradas no procedimento prometem um processo imparcial para a fundamentação e avaliação de princípios" ${ }^{45}$. Ou seja, ele comunga com Weber um certo ceticismo quanto à correção dos conteúdos, implicando, como contrapartida, que se deva analisar, como opção, o núcleo racional do procedimento. Nesse sentido, o próprio contratualismo ou o imperativo categórico poderiam ser entendidos como procedimentos: “o modelo do contrato social, do mesmo modo que o imperativo categórico, pode ser entendido como proposta para um processo, cuja racionalidade garante a correção de qualquer tipo de decisão tomada conforme um procedimento" 46 . No entanto, o procedimento não pode ele próprio ser despido de uma racionalidade prática. Weber teria sido levado a isso por não conseguir conceber uma racionalidade para além da instrumental, mas que, como visto, tal racionalidade seria operante em Weber pace ele mesmo.

\section{O modelo de Hobbes}

O problema formulado por Hobbes é o da produção da ordem social a partir dos interesses dos indivíduos ou das partes que compõem a sociedade: "Na sua forma clássica, o problema hobbesiano tinha se colocado da forma seguinte: de que modo o encontro das perspectivas egocêntricas de indivíduos que agem no interesse próprio pode produzir uma ordem capaz de obrigar os atores individuais a levar em conta os interesses dos outros" ${ }^{\prime 7}$. Segundo Habermas, o ponto de partida de Hobbes diz respeito a "ações dirigidas por interesses de egoístas racionais ou, como diria Kant, de um 'povo de demônios" "48. Isso significa uma atitude orientada para o sucesso no estado de natureza, com base na racionalidade estratégica. Esse ponto de partida, Habermas o caracteriza como o da primeira pessoa do singular. Porém, esta

45 TrFG2 p. 213 [FG p.562-3].

${ }^{46}$ TrFG2 p. 201-2 [FG p.550].

47 HABERMAS, J. Direito e democracia: entre faticidade e validade. v. II. Trad. F. B. Siebeneichler: Faktizität und Geltung: Beiträge zur Diskurstheorie des Rechts und des demokratischen Rechtsstaats. Rio de Janeiro: Tempo Brasileiro, 1997, p.78.

48 HABERMAS, J. Direito e democracia: entre faticidade e validade. [v. I]. [Trad. F. B. Siebeneichler: Faktizität und Geltung: Beiträge zur Diskurstheorie des Rechts und des demokratischen Rechtsstaats]. Rio de Janeiro: Tempo Brasileiro, 1997, p. 123. 
não seria a perspectiva de análise para "trocar suas liberdades de ação naturais - conflitantes, porém ilimitadas - pelas liberdades do direito privado, Isto é, as que são compatibilizadas e limitadas segundo leis gerais"49. Na verdade, duas condições seriam necessárias para fazer a transição do conflito à cooperação:

Em primeiro lugar é preciso entender o que é um contrato. Todavia, para a compreensão da ideia de reciprocidade do contrato precisar-se-ia da perspectiva da segunda pessoa do singular, ou seja, as partes "teriam que poder compreender o significado geral de uma relação social apoiada no princípio da reciprocidade" "50. Porém, eles não dispõem dessa cognição, pois a sua perspectiva no estado de natureza é aquela da primeira pessoa que atua estrategicamente, ou seja, eles "ainda não aprenderam, antes de qualquer socialização, a assumir a perspectiva de um outro e a considerar-se a si mesmos na perspectiva de uma segunda pessoa. Sem isso, sua própria liberdade é considerada simplesmente como uma liberdade que bate contra obstáculos fáticos, não podendo ser vista como uma liberdade constituída através do reconhecimento recíproco ${ }^{51}$.

Em segundo lugar, é necessário entender o contrato social. Para tal, precisaria um afastamento ainda maior de si, pois implicaria um descentramento do eu capaz de assumir a primeira pessoa do plural, ou seja, as partes "teriam que poder assumir a perspectiva social de uma primeira pessoa no plural - que o autor Hobbes e seus leitores sempre assumiram tacitamente -, a qual, no entanto, está vedada aos sujeitos no estado natural' ${ }^{52}$. Esse ponto de vista seria necessário para julgar da simetria e da reciprocidade das normas necessárias para se instituir uma ordem social aceitável por todos, ou seja, trata-se da possibilidade de conceber "se a reciprocidade da coerção, que limita o arbítrio de cada um segundo leis gerais, é do interesse simétrico de todos, podendo, por isso, ser querida por todos os participantes" 53 .

A regra de ouro, usada por Hobbes ${ }^{54}$, alega Habermas, seria o reconhecimento do "tipo de argumentos morais que entram nesse jogo" 55 .

${ }^{49}$ HABERMAS, J. Direito e democracia: entre faticidade e validade. [v. I]. [Trad. F. B. Siebeneichler: Faktizität und Geltung: Beiträge zur Diskurstheorie des Rechts und des demokratischen Rechtsstaats]. Rio de Janeiro: Tempo Brasileiro, 1997, p.124.

50 Idem, ibidem, p.124.

51 Idem, ibidem, p.124.

52 HABERMAS, J. Direito e democracia: entre faticidade e validade. [v. I]. [Trad. F. B. Siebeneichler: Faktizität und Geltung: Beiträge zur Diskurstheorie des Rechts und des demokratischen Rechtsstaats]. Rio de Janeiro: Tempo Brasileiro, 1997, p.125.

53 Idem, ibidem, p. 125.

54 "Quod tibi fieri non vis, alteri ne feceris" (HOBBES, T. Leviathan, or Matter, Form, and Power of a Commonwealth Ecclesiastical and Civil. (Edited by C.B. Macpherson). London: Penguin, 1968, Chap. XIV).

55 HABERMAS, J. Direito e democracia: entre faticidade e validade. [v. I]. [Trad. F. B. Siebeneichler: Faktizität und Geltung: Beiträge zur Diskurstheorie des Rechts und des demokratischen Rechtsstaats]. Rio de Janeiro: Tempo Brasileiro, 1997, p.125. 
Ora, é o próprio Hobbes quem confessa que a regra de ouro é a suma da lei natural. Ele a cita em sua forma negativa logo depois da segunda lei natural no cap. XIV do Leviathan. Cita-a também na sua forma positiva, como resumo de todas as leis, depois da décima nona lei de natureza no cap. XV e, novamente, como resumo de todas leis naturais, na sua forma negativa no cap. XXVI. Contudo, tais argumentos morais que a regra de outro introduz estariam em contradição com a sua perspectiva inicial de fundamentação de normas com base em um sistema do egoísmo bem ordenado, com fundamento no autointeresse esclarecido dos indivíduos ${ }^{56}$.

Com isso, ele não quer dizer que a regra de ouro seja o modo mais acurado para se conseguir tais argumentos. Essa é a razão pela qual ele afirma que a regra de ouro aponta para a espécie de argumentos morais que seriam exigíveis para o caso:

Hobbes reconheceu o tipo de argumentos morais que entram nesse jogo, nas passagens em que ele recorre à regra de ouro, tida como uma lei natural - Quod tibi fieri non vis, alteri ne feceris. Porém, tal impregnação moral do estado natural está em contradição com os pressupostos naturalistas da prova que ele pretende atingir, a saber, fundamentar a construção de um sistema do egoísmo bem ordenado, a partir do autointeresse esclarecido de todos os indivíduos ${ }^{57}$.

Ou seja, tratar-se-ia de uma indicação da perspectiva de reciprocidade das regras, restando determinar ainda, amiúde, se a regra de ouro consegue operacionalizar tal perspectiva. Forçoso concluir, também, a partir dessa perspectiva, que Habermas interpreta as teorias da lei natural como sendo baseadas na moral, incluso a de Hobbes, o que ele sabidamente critica ${ }^{58}$. Vale a pena anotar que Habermas inclui também Kant e Rawls na tradição do direito natural moderno. Esses três filósofos constituem uma sólida tradição de tratamento do direito e da ordem social em relação à qual Habermas apresentará a sua própria teoria discursiva do direito. Desse modo, parece que Habermas tem que ficar a meio caminho entre uma fundamentação contratualista, para ele insuficiente, e uma fundamentação moral, para ele também problemática ${ }^{59}$. O que unificaria os três autores seria a conexão entre

\footnotetext{
56 Idem, ibidem, p.125.

57 Idem, ibidem, p. 125.

58 HABERMAS, J. Direito e democracia: entre faticidade e validade. [v. II]. [Trad. F. B. Siebeneichler: Faktizität und Geltung: Beiträge zur Diskurstheorie des Rechts und des demokratischen Rechtsstaats]. Rio de Janeiro: Tempo Brasileiro, 1997, p.321.

${ }^{59}$ A outra teoria enfrentada por Habermas é aquela do positivismo jurídico: "a nau da teoria do discurso navega entre os escolhos do direito natural e do positivismo do direito" [HABERMAS, J. Direito e democracia: entre faticidade e validade. [v. II]. [Trad. F. B. Siebeneichler: Faktizität und Geltung: Beiträge zur Diskurstheorie des Rechts und des demokratischen Rechtsstaats]. Rio de Janeiro: Tempo Brasileiro, 1997, p.313-4).
} 
a explicação da ordem social, do direito e da moral, de tal forma que se operaria uma fundamentação moral do direito, o que ele imputa estranhamente também a Hobbes, como se pode inferir da parte da referência anterior, segundo a qual a regra de ouro seria uma espécie de confissão de que estariam a operar no argumento hobbesiano, sub-repticiamente, razões morais. Como dito, a regra de ouro sugeriria, exatamente, o tipo de argumento moral que seria necessário na explicação da ordem social, sem, contudo, conseguir ofertar tal argumento.

Nesse sentido, Habermas, filia-se ao lado dos que aceitam a crítica kantiana à regra de ouro. Em nota ao texto da Fundamentação, Kant afirma que a regra de ouro, que ele cita apenas em sua formulação negativa, só pode ser entendida como derivada do imperativo categórico, não o contrário, e ainda assim com várias limitações:

\begin{abstract}
Não se pense que o trivial: quod tibi non vis fieri etc. possa servir aqui de norma ou princípio. Pois ele é, se bem que com diversas restrições, tão-somente derivado daquele; não pode ser uma lei universal, visto que não contém o fundamento dos deveres para consigo mesmo, nem dos deveres do amor aos outros (pois muitos topariam de bom grado que os outros não lhes fizessem o bem desde que pudessem se dispensar de se mostrar benfazejos a eles), nem tampouco, por fim, dos deveres exigíveis de uns para com os outros; pois o criminoso argumentaria com base nisso contra o juiz que lhe dita uma pena, etc. ${ }^{60}$.
\end{abstract}

Kant não diz quais limitações seriam necessárias para tal derivação, contudo, ele parece sustentar que se a regra de ouro fosse tomada sem qualquer limitação, ela não fundamentaria dever de tipo algum, devido, justamente, à preponderância da perspectiva do eu. Segundo Rawls, o que Kant critica na regra de ouro é que ela permite que as inclinações e circunstâncias pessoais tenham um papel no raciocínio prático, o que não seria o caso com o imperativo categórico ${ }^{61}$. No exemplo de Kant, o criminoso opera a regra de ouro a partir do seu desejo de não ser punido, o que gera a conclusão de que ninguém quer ser punido e de que, portanto, ninguém pode punir porque também não quer ser punido. Por outro lado, a inconsistência que o não seguimento do imperativo categórico gera é mais radical do que a determinada pela regra de ouro, já que este não depende de tais

60 KANT, I. Fundamentação da metafísica dos costumes. (Trad. G. A. de Almeida: Grundlegung zur Metaphysik der Sitten). São Paulo: Discurso Editorial/Barcarolla, 2009, p.430 nota [MS, AA 06: 430 nota).

${ }^{61}$ RAWLS, J. Lectures on the History of Moral Philosophy. Cambridge: Harvard University Press, 2000, p.199. 
particularidades, as quais, então, desempenham um papel impróprio na deliberação prática ${ }^{62}$.

Segundo Habermas, a regra de ouro tem um caráter egocêntrico que o imperativo categórico em tese não teria, contudo, se o imperativo categórico for operacionalizado de forma monológica, ele se aproxima do caráter egocêntrico da regra de outro ${ }^{63}$. Nesse particular, a rigor, para ele, nem o imperativo categórico é acurado o suficiente, haja vista a sua ética discursiva ser justamente uma reformulação do imperativo categórico para suprir essa operacionalização monológica do mesmo ${ }^{64}$. Nesse particular, a acusação por ele endereçada ao imperativo categórico é semelhante àquela que ele imputa a Rawls.

Ora, o que ele acusa no neocontratualismo de Rawls é justamente uma perspectiva egocêntrica, a qual deve ser estendida também ao imperativo categórico, como ver-se-á a seguir. Deveras, a acurácia do posicionamento de Habermas, em relação ao contratualismo e à tradição moderna do direito natural, pode ser melhor vislumbrada na crítica que ele endereça ao neocontratualismo de Rawls ${ }^{65}$, importando anotar que Habermas interpreta a teoria da justiça de Rawls como o retorno do direito natural moderno ${ }^{66}$.

Ademais, ele sustenta que as limitações à regra de ouro ou à racionalidade estratégica que opera a partir de primeira pessoa, limitações essas para que ela seja compatível com o imperativo categórico, porta natureza substantiva ${ }^{67}$. Certamente, é justificada a ignorância da religião, da classe social, do sexo, da cor da pele, mas por que não também a ignorância da beleza, já

62 "What Kant must mean is that, to be reasonable, the criminal must assess the judge's action by reasoning in accordance with the $\mathrm{Cl}$-procedure and not in terms of the criminal's own situation and desire not to be punished. What is wrong with the Golden Rule (in both its positive and negative versions) is that as stated it allows our natural inclinations and the special circumstances to play an improper role in our deliberations. But in saying this Kant implies that the Cl-procedure specifies their proper role" (RAWLS, J. Lectures on the History of Moral Philosophy. Cambridge: Harvard University Press, 2000, p.199).

${ }_{63}$ HABERMAS, J. A inclusão do outro: estudos de teoria política. [Trad. G. Sperber, P. A. Soethe, M. C. Mota: Die Einbeziehung des Anderen: Studien zur politischen Theorie]. 2. ed., São Paulo: Loyola, 2004, p.70-71.

64 VOLPATO DUTRA, D. J. Kant e Habermas: a reformulação discursiva da moral kantiana. Porto Alegre: EDIPUCRS, 2002.

65 HABERMAS, J. "Reconciliation through the Public Use o Reason: Remarks on John Rawl's Political Liberalism". In: The Journal of Philosophy. New York: v.92, n.3, p.109-31, March 1995. HABERMAS, J. The Inclusion of the Other: Studies in Political Theory. [Transl. Ciaran Cronin: Die Einbeziehung desanderen Studien zur politischen Theorie]. Cambridge: MIT Press, 1998 [1996].

${ }_{66}$ HABERMAS, J. Direito e democracia: entre faticidade e validade. [v.I]. [Trad. F. B. Siebeneichler: Faktizität und Geltung: Beiträge zur Diskurstheorie des Rechts und des demokratischen Rechtsstaats]. Rio de Janeiro: Tempo Brasileiro, 1997, p.83 s.

${ }^{67}$ HABERMAS, J. Reconciliation through the Public Use of Reason: Remarks on John Rawl's Political Liberalism. The Journal of Philosophy. New York: v.92, n.3, p.109-31, March 1995. 
que isso afeta a autoestima que é um bem primário, do ser nascido ou não, pois isso teria efeito sobre o aborto, dos talentos genéticos, já que isso tem efeito sobre políticas de eugenia, do país ao qual se pertence, pois as fronteiras nas quais se nasce determinam profundamente as condições para a felicidade de alguém, etc. Nesse sentido, observa Habermas, o ponto central da justificação dos princípios de justiça é menos a deliberação na posição original e mais a justificação das intuições do que compõe a própria posição original. Isso ocorre porque a posição original é um procedimento prenhe de conteúdo normativo que precisa ser justificado, como o conceito de pessoa que deve ter um senso de justiça e a sua capacidade para ter uma concepção de bem ${ }^{68}$. Isso soa como o predicado da autoconservação que tem que ser pressuposto por Hobbes para que se sigam as leis naturais.

\section{O modelo de Kant}

O conceito kantiano de direito é constituído de modo tal que, muito embora não exija motivação moral para o seu cumprimento, tem que ser compatível com tal motivação moral: "As Kant recognized, law differs from morality in the formal properties of legality. Certain aspects of conduct open to moral assessment (for example, convictions and motives) are per se exempted from legal regulation" ${ }^{6}$. O importante é que com a legalidade se faz uma abstração do móbil (ohne Rücksicht auf die Triebfeder derselben) ${ }^{70}$. Sabidamente, a legalidade concerne à relação externa da ação com respeito à sua conformidade ou não conformidade à regra que a enforma. A legislação jurídica não exige que a própria idéia do dever, que é interna, se erija em motivo determinante da ação, liberando, por consequência, a interioridade. Em suma, "a doutrina do direito e a doutrina da virtude, se distinguem, então, bem menos por deveres diferentes que pela diferença de legislação que associa à lei um móbil antes que um outro"’1.

Moral e direito são, portanto, conceitualmente distintos sob o ponto de vista da motivação (interna e externa), mas não são, em princípio, incompatíveis, nem sob o ponto de vista da justificação, nem quanto à

68 HABERMAS, J. A inclusão do outro: estudos de teoria politica. [Trad. G. Sperber, P. A. Soethe, M. C. Mota: Die Einbeziehung des Anderen: Studien zur politischen Theorie]. 2. ed., São Paulo: Loyola, 2004, p.73. HABERMAS, J. Reconciliation through the Public Use o Reason: Remarks on John Rawl's Political Liberalism. The Journal of Philosophy. New York: v.92, n.3, p.109-31, March 1995.

69 HABERMAS, J. The Inclusion of the Other: Studies in Political Theory. Cambridge: MIT Press, 1998, p.201.

70 KANT, I. A metafísica dos costumes. (Trad. J. Lamego). Lisboa: Fundação Calouste Gulbenkian, 2005, MS, AA 06: 219.

71 Idem, ibidem, MS, AA 06: 220. 
motivação ${ }^{72}$. Tal compatibilidade/incompatibilidade tem como fundamento o fato de que para "leis idênticas, as máximas dos agentes podem ser muito diferentes" "73. O acordo da ação com a lei é a legalidade; já o acordo da máxima da ação com a lei é a moralidade. A máxima é um princípio de ação que o sujeito se dá por norma, de tal forma que para a mesma lei concorrem diferentes máximas ${ }^{74}$. A legislação ética é, portanto, imperfeita, por admitir somente a coerção interna. Ao passo que a jurídica seria perfeita, por admitir as duas. Então, a legislação moral só admite uma motivação, qual seja, a própria lei moral. Sendo que "o direito é a suma de condições pelas quais o arbítrio de um pode concordar com o arbítrio de outro segundo uma lei universal de liberdade" 75 , não se pode exigir que esse princípio, qual seja, limitar a liberdade para que ela possa conviver com a liberdade dos outros, possa ser exigido como máxima para a ação de qualquer um. Este, certamente, é um dever ético, mas que releva do campo do direito.

Resulta da formulação kantiana que a coerção exige a ação externa, mas libera o interior, a motivação. A moral, ao exigir que o motivo da ação seja o próprio dever, exige uma total transparência do interior, dominando, completamente, a vontade, não deixando a ela espaço algum de mobilidade. Se, por um lado, a moral libera a ação externa do cálculo de consequências, imputando, mesmo, falta de valor moral a tal cálculo, na medida em que a pureza da vontade dá todo o valor moral, já que o importante no valor moral da ação é tão somente a vontade boa, ela, de outro lado, domina a vontade livre com uma determinação unitária, ao lhe exigir motivação exclusiva, calcada na pureza do próprio ordenamento moral. Como bem pontua Habermas, "a positividade do direito força uma divisão da autonomia, que não possui equivalente no campo moral. A autodeterminação moral constitui um conceito unitário" 76 . Não fosse assim, cairia por terra o elemento mesmo que distingue as duas legislações.

O direito exige a conformidade à legislação, descompromissando a motivação com relação aos elementos nos quais se prenderá. Tal economia, por não querer penetrar no âmago da vontade, se contenta apenas com a exterioridade, a qual é, então, objetivamente calculável e perceptível, ao

72 VOLPATO DUTRA, D. J. Manual de Filosofia do Direito. Caxias do Sul: Educs, 2008.

${ }^{73}$ KANT, I. A metafísica dos costumes. (Trad. J. Lamego). Lisboa: Fundação Calouste Gulbenkian, 2005, MS, AA 06: 225.

74 Idem, ibidem, MS, AA 06: 225.

75 KANT, I. A metafísica dos costumes. (Trad. J. Lamego). Lisboa: Fundação Calouste Gulbenkian, 2005, MS, AA 06: 230.

76 HABERMAS, J. Direito e democracia: entre faticidade e validade. [v.l]. Rio de Janeiro: Tempo Brasileiro, 1997, p.310, posfácio. 
contrário da motivação moral, sempre de difícil vislumbre, dada a pureza que se lhe exige. Logo, da coatividade da conduta se segue uma incongruência com a disciplina da própria vontade no agir por dever. De fato, afirma Kant:

[...] quem, quando sente em si a presença do móbil determinando-o à observação do dever, conhece-se o bastante para saber se este móbil procede inteiramente da representação da lei ou se não há concorrentemente muitos outros impulsos, sensíveis, que são orientados a uma vantagem (ou à prevenção de uma desvantagem) e que, em outras circunstâncias, poderiam estar inteiramente a serviço do vício?77

Portanto, o verso da medalha do aspecto coativo do direito é, precisamente, a liberação da vontade da motivação moral, facultando-lhe a indeterminação do arbítrio. Tal verso pode ser expresso na gramática dos direitos subjetivos. Ou seja, a necessária coatividade do direito implica na liberação da vontade, conferindo-lhe, destarte, direitos subjetivos de ação, cuja única formulação possível consiste na chamada liberdade negativa de abandonar a motivação da lei pela lei:

a autonomia privada de um sujeito pode ser entendida essencialmente como a
liberdade negativa de retirar-se do espaço público das obrigações ilocucionárias
recíprocas para uma posição de observação e de influenciação recíproca. A
autonomia privada vai tão longe, que o sujeito do direito não precisa prestar
contas, nem apresentar argumentos publicamente aceitáveis para seus planos de
ação. Liberdades de ação subjetivas justificam a saída do agir comunicativo e a
recusa de obrigações ilocucionárias; elas fundamentam uma privacidade que
libera do peso da liberdade comunicativa atribuída e imputada reciprocamente ${ }^{78}$.

Essa liberdade negativa é o princípio supremo de uma gramática da vontade indeterminada, cujo petardo mais evidente está nessa formulação: o que a lei não pró́be, ela permite. Ou seja, o espaço positivo da liberdade, a qual deve ser exercida dentro da limitação do direito, é apenas uma expressão desta liberdade radical de se liberar da moral. Fica aberto, dessa forma, o espaço propriamente jurídico no qual a vontade livre se exerce. É assim que se pode entender por que o verso da medalha do aspecto coercitivo do direito reside nos direitos subjetivos de ação, por mais contrario sensu que pareça, pois, o verso da medalha da coerção, por razões categoriais, tem que ser a liberação da vontade da obediência por dever à legislação.

A análise que Habermas faz da filosofia do direito kantiana mostra que ela é ambivalente. Kant por uma série de abstrações configura uma concepção de direito que mais parece a moral travestida pela roupagem da

77 KANT, I. A metafísica dos costumes. (Trad. J. Lamego). Lisboa: Fundação Calouste Gulbenkian, 2005, MS, AA 06: 447.

78 HABERMAS, J. Direito e democracia: entre faticidade e validade. [v.l]. Rio de Janeiro: Tempo Brasileiro, 1997, p.156. 
coação. Tanto a sua definição de direito, quanto o princípio universal do direito, são interpretados por Habermas como um direito subordinado à moral. De fato, Kant desloca sutilmente a definição de direito da formulação deste como coação, "Direito e faculdade de coagir significam, portanto, a mesma coisa"79, para esta outra formulação, "o direito estrito pode ser representado também como a possibilidade de uma coação recíproca geral concordante com a liberdade de qualquer um segundo leis universais" $" 80$. Ou seja, trata-se, neste último caso, de uma definição normativa referida ao que é justo ${ }^{81}$. Com isso, a liberdade do homem e a igualdade (veja-se que aparece na formulação os termos "geral" e "universais") são claramente estabelecidas. Note-se, contudo, que já no texto Contra Hobbes de 1793, ele houvera estabelecido uma relação entre o único direito humano inato, a liberdade, e o sistema jurídico como um sistema de leis:

Todo o direito depende, de fato, das leis. Mas uma lei pública que determina para todos o que lhes deve ser juridicamente permitido ou interdito é o ato de um querer público, do qual promana todo o direito e que, por conseguinte, não deve por si mesmo cometer injustiças contra ninguém. Ora, a este respeito, nenhuma outra vontade é possível a não ser a de todo o povo (já que todos decidem sobre todos e, por conseguinte, cada um sobre si mesmo): pois, só a si mesmo é que alguém pode causar dano ${ }^{82}$.

Segundo Habermas, isso significa que a autonomia moral só pode adquirir figuração concreta pela autonomia política, de tal forma que "o princípio do direito parece realizar uma mediação entre o princípio da moral e o da democracia. Contudo, não está suficientemente claro como esses dois princípios se comportam reciprocamente" ${ }^{83}$. Para se entender isso, deve-se esclarecer que a vontade pública do republicanismo Habermas chama-a de democracia. Ele sugere uma aproximação entre o que Kant nominou republicanismo e o que hoje se chama democracia ${ }^{84}$.

Kant muito bem observa tratar-se da vontade pública de todo o povo, pois somente quando se tratar da vontade de todo o povo é que não poderá haver injustiça contra alguém. É essa a ideia que ele repete alguns anos

${ }^{79}$ KANT, I. A metafisica dos costumes. (Trad. J. Lamego). Lisboa: Fundação Calouste Gulbenkian, 2005, MS, AA 06: 232.

80 Idem, ibidem, MS, AA 06: 232.

81 ldem, ibidem, MS, AA 06: 229.

82 KANT, I. Sobre a expressão corrente: isso pode ser correcto na teoria, mas nada vale na prática. (Trad. Artur Morão). Covilhã: Lusofia Press. (Disponivel em: http://www.lusosofia.net), TP, AA 08: 294-5. ${ }_{83}$ HABERMAS, J. Direito e democracia: entre faticidade e validade. [v. I]. Rio de Janeiro: Tempo Brasileiro, 1997, p.127.

${ }^{84}$ Idem, ibidem, p. 122. 
depois na Doutrina do direito e que Habermas ${ }^{85}$ considera como uma formulação kantiana da soberania tal qual definida por Rousseau ${ }^{86}$ :

O poder legislativo somente pode caber à vontade unificada do povo. Pois, uma vez que deve proceder dele todo direito, não deve ele por sua lei poder ser injusto pura e simplesmente com ninguém. Ora, se alguém decide algo em relação a um outro, sempre é possível que assim ele seja injusto com ele, mas nunca naquilo que ele decide acerca de si mesmo (pois volenti non fit injuria). Assim, somente a vontade concordante e unificada de todos, na medida em que cada um decide o mesmo sobre todos e todos sobre um, portanto somente a vontade universalmente unificada do povo é legisladora ${ }^{87}$.

Nesse sentido, poder-se-ia perguntar, como ficaria a relação entre o direito racional e a vontade unida do povo, quando esta estabelecesse leis com conteúdo contrário ao direito racional. Essa não parece ser uma possibilidade para Kant, pois o cidadão não poderia concordar com leis que desrespeitassem tal direito: "todo o homem tem os seus direitos inalienáveis a que não pode renunciar, mesmo se quisesse, e sobre os quais tem competência para julgar" De fato, pode-se afirmar que há uma correspondência entre todos poderem concordar e cada um não poder discordar, de tal forma que não haveria, segundo Habermas, uma limitação da vontade unida do povo pelo direito racional, haja vista, justamente, os cidadãos não poderem dar seu consentimento a leis que neguem seus direitos humanos.

Kant não explica se a razão pela qual o cidadão não pode concordar com leis contrárias à liberdade decorre de uma capacidade moral ou de um mecanismo referido à generalidade da lei jurídica que acaba por fazer reverter sobre o indivíduo o que ele legisla para os outros, em uma espécie de regra de ouro. Habermas sugere esta interpretação em 1988:

E, para que a razão legitimadora do poder não se anteponha mais à vontade soberana do povo - como em Locke - situando os direitos humanos num estado natural fictício, atribui-se uma estrutura racional à própria autonomia da

$85 \mathrm{Idem}$, ibidem, p.259.

86 "Ces clauses, bien entendues, se réduisent toutes à une seule - savoir, l'aliénation totale de chaque associé avec tous ses droits à toute la communauté: car, premièrement, chacun se donnant tout entier, la condition est égale pour tous; et la condition étant égale pour tous, nul n'a intérêt de la rendre onéreuse aux autres. De plus, l'aliénation se faisant sans réserve, l'union est aussi parfaite qu'elle peut l'être, et nul associé n'a plus rien à réclamer: car, s'il restait quelques droits aux particuliers, comme il n'y aurait aucun supérieur commun qui pût prononcer entre eux et le public, chacun, étant en quelque point son propre juge, prétendrait bientôt l'être en tous; l'état de nature subsisterait, et l'association deviendrait nécessairement tyrannique ou vaine" (ROUSSEAU, J. Du contrat social. Paris: Aubier, 1943 [1757], livre I, ch. VI].

87 KANT, I. A metafísica dos costumes. (Trad. J. Lamego). Lisboa: Fundação Calouste Gulbenkian, 2005, MS, AA 06: 313-314.

88 KANT, I. Sobre a expressão corrente: isso pode ser correcto na teoria, mas nada vale na prática. (Trad. Artur Morão). Covilhã: Lusofia Press. (Disponivel em: http://www.lusosofia.net), TP, AA 08: 304. 
prática da legislação. Uma vez que a vontade unida dos cidadãos só pode manifestar-se na forma de leis gerais e abstratas, é forçada per se a uma operação que exclui todos os interesses não generalizáveis, admitindo apenas as normatizações que garantem a todos iguais liberdades. O exercício da soberania popular garante, pois, os direitos humanos ${ }^{89}$.

Em 1992, porém, ele atribui isso claramente a Rousseau, mas afirma, por duas vezes, não haver clareza em Kant sobre o assunto ${ }^{90}$, sendo que tal falta de clareza dever-se-ia, basicamente, a Kant ter operacionalizado a autonomia dos sujeitos no exercício da soberania popular segundo o imperativo categórico: "porém ele explica esse conceito (autonomia) na fórmula legal do imperativo categórico" $"$.

Evidentemente, como não pode haver a vontade unida efetivamente operante, a leis devem ser feitas como se pudessem contar com o acordo de todo o povo:

[...] se, por conseguinte não se pode esperar unanimidade de um povo inteiro, se, portanto, apenas se pode prever como alcançável uma maioria de votos e, claro está, não a partir dos votantes diretos (num povo grande), mas apenas dos delegados enquanto representantes do povo, então, o próprio princípio que consiste em contentar-se com esta maioria, e enquanto princípio admitido com o acordo geral, portanto, mediante um contrato, é que deverá ser o princípio supremo do estabelecimento de uma constituição civil ${ }^{92}$.

No mesmo sentido, em Teoria e práxis, ele afirma que a vontade geral é uma ideia da razão que

obriga todo legislador a fornecer as suas leis como se elas pudessem emanar da vontade coletiva de um povo inteiro, e a considerar todo o súdito, enquanto quer ser cidadão, como se ele tivesse assentido pelo seu sufrágio a semelhante vontade. E esta, com efeito, a pedra de toque da legitimidade de toda a lei pública. Se, com efeito, esta é de tal modo constituída que é impossivel a um povo inteiro poder proporcionar-lhe o seu consentimento (...) não é justa; mas se é apenas possiviel que um povo the dê o se assentimento, então é um dever considerar a lei como justa ${ }^{93}$.

Desse modo, quando ele operacionaliza a vontade unida do povo, o direito racional da liberdade garantido de forma moral ancora em um sujeito que não pode deixar de querer tal direito, embora possa errar, haja vista as leis nunca demandarem efetivamente a manifestação de todos os concernidos por ela. No caso de Kant, em última análise, ter-se-ia, portanto, que apelar a um

89 HABERMAS, J. Direito e democracia: entre faticidade e validade. [v. II]. Rio de Janeiro: Tempo Brasileiro, 1997, p.259.

90 Idem, ibidem, p.127-8.

91 Idem, ibidem, p.127-8.

92 TP, AA 08: 296.

${ }^{93}$ KANT, I. Sobre a expressão corrente: isso pode ser correcto na teoria, mas nada vale na prática. (Trad. Artur Morão). Covilhã: Lusofia Press. (Disponivel em: http://www.lusosofia.net/), TP, AA 08: 297. 
sujeito moral que não pode se recusar a dar seu consentimento aos direitos humanos. Dito lapidarmente, o que se registra em Kant é um déficit de operacionalização da forma jurídica quando ele trata da relação entre a vontade individual e a coletiva. Ou seja, Kant exagera na moralização do direito. Como se verá, o problema de Rousseau é outro, ele exagera na concretude da forma de vida como condição para sustentar o acordo da vontade privada e da vontade geral.

O ponto de Habermas, quiçá, é que em Kant o indivíduo já entra no contrato equipado com um direito, o qual ele não abrirá mão ou não pode concordar em abrir mão. Desse modo, pode-se afirmar que esse direito fundamentado moralmente na humanidade como fim em si mesma adentraria na vontade soberana do povo e adentraria também no direito positivo. No fundo, Habermas está acusando Kant de ter operacionalizado a vontade geral de forma individualista, via imperativo categórico, nos termos da filosofia da consciência, e não por um procedimento discursivo de viés jurídico.

$\mathrm{Na}$ verdade, Kant é ambivalente porque tem uma estratégia dupla. Por um lado, ele não tem como manter uma motivação moral como fundamento do direito, isso por razões analíticas, vis-à-vis da sua definição do que consiste uma ação por dever. Ora, não se pode impor coativamente a prática de uma ação por dever. Por outro lado, sob o ponto de vista do conteúdo, o direito racional continua vinculado à moral, como uma espécie de aplicação do imperativo categórico a relações externas, muito bem sublinhado por Gregor ${ }^{94}$.

\section{O modelo de Rawls}

Segundo Cohen, a posição original é uma máquina produtora de justiça ${ }^{95}$. A posição original não pede que o sujeito contratante precise sair da própria perspectiva. Isso ocorre porque o mecanismo que a engendra deve ser capaz de forçar a mudança do papel e do significado dos interesses individuais. Deveras, para Habermas, a posição original é uma estrutura que deveria determinar a mudança do papel e do significado dos interesses individuais ${ }^{96}$, porém, ela não consegue tal desiderato, visto que isso só se tornaria possível pela assunção de uma perspectiva intersubjetiva. No caso de Hobbes, seria a

${ }^{94}$ GREGOR, M. J. Law of Freedom: A Study of Kant's Method of Applying the Categorical Imperative in the 'Methapysik der Sitten'. Oxford: Blackwell, 1963.

${ }_{95}$ COHEN, G. A. Rescuing Justice and Equality. Cambridge: Harvard University Press, 2008, p.5.

96 HABERMAS, J. The Inclusion of the Other: Studies in Political Theory. [Transl. Ciaran Cronin: Die Einbeziehung desanderen Studien zur politischen Theorie]. Cambridge: MIT Press, 1998 [1996], p.81. 
junção do interesse na autoconservação com a incerteza ${ }^{97}$ no estado de guerra que determinaria tal mudança no sentido dos interesses. Nesse sentido, o argumento que Hobbes movimentou contra o louco visaria a mostrar como o interesse do contratante se coaduna com o cumprimento do contrato, mesmo que o outro já tenha previamente cumprido a sua parte. De fato, o que Hobbes alega contra o louco é justamente que o seu cálculo da vantagem que adviria de descumprir o contrato só aconteceria por acaso, logo, não seria racional descumpri-lo. Mutatis mutandis, no caso de Rawls, os interesses consistem em assegurar bens primários e a incerteza é modelada pelas condições de ignorância da posição original.

De acordo com o juízo de Habermas, as limitações do design da posição original são "morally substantive situational constraints" permitem que as partes não precisem assumir o ponto de vista moral, pois tais limitações fariam com que o seu próprio interesse refletita o ponto de vista daquilo que é bom para todos, porque, em sendo assim, seria bom para elas também individualmente: "they find themselves constrained already by their self-interest to reflect on what is equally good for all" "99. Essa seria justamente a tentativa de Rawls de modelar a posição original nos termos de uma teoria da decisão racional: "This construction of an original position that frames the freedom of choice of rational actors in a reasonable fashion is explained by Rawls's initial intention of representing the theory of justice as part of the general theory of choice" 100 .

Um dos problemas que Habermas detecta está justamente nas condições que modelam a posição original e que lhe dão razoabilidade, tornando-a equitativa (fair), pois haveria uma espécie de prioridade dessas condições de razoabilidade sobre a decisão racional que viria a resultar do seu funcionamento na posição original. Habermas de fato cita um texto de Rawls no qual ele próprio reconhece isso, qual seja,

The Reasonable, then, is prior to the Rational, and this gives the priority of right. Thus, it was an error in Theory (and a very misleading one) to describe a theory of justice as part of the theory of rational choice [...]. There is no thought of trying to derive the content of justice within a framework that uses

${ }^{97}$ RAWLS, J. Lectures on the History of Political Philosophy. Cambridge, MA: Harvard University Press, 2007, p.69.

98 HABERMAS, J. The Inclusion of the Other: Studies in Political Theory. [Transl. Ciaran Cronin: Die Einbeziehung desanderen Studien zur politischen Theorie]. Cambridge: MIT Press, 1998 [1996], p.51.

${ }^{99}$ Idem, ibidem, p.52.

100 Idem, ibidem, p.52. 
an idea of the rational as the sole normative idea. That thought is incompatible with any kind of Kantian view ${ }^{101}$.

Sabidamente, ele repete essa mesma critica em Political Liberalism ${ }^{102}$. Desse modo, seria o próprio Rawls a reconhecer uma preponderância de condições básicas de caráter normativo prévias à posição original, de tal forma que, bem compreendida, a justiça como equidade seria, sim, uma concepção política de justiça, mas de caráter moral: "a political conception of justice, which is, of course, a moral conception" 103 .

Resta agora pensar nas consequências de uma tal afirmação para o seu construtivismo. Ora, se a teoria pressupõe uma razoabilidade prévia ao que resulta da posição original, qual o estatuto dessa razoabilidade. $\mathrm{Na}$ interpretação de Habermas, tal razoabilidade portaria determinações substantivas em vez de processuais ${ }^{104}$ :

\footnotetext{
The decisive issue in the justification of the two highest principles of justice is less the deliberations in the original position than the intuitions and basic concepts that guide the design of the original position itself. Rawls introduces normative contents into the very procedure of justification, above all those ideas he associates with the concept of the moral person: the sense of fairness and the capacity for one's own conception of the good ${ }^{105}$.
}

A conclusão que se segue, portanto, é que o conceito de pessoa não é construído, mas pressuposto pela posição original: "His concept of the person as well oversteps the boundaries of political philosophy"106.

O construtivismo, assim compreendido, tem estreita conexão com o kantismo. Ora, duas interpretações de Kant podem ser concebidas a esse respeito, uma delas de caráter mais intuicionista e outra de caráter mais construtivista.

101 RAWLS, J. Justice as Fairness: Political not Metaphysical. Philosophy and Public Affairs. v.14, n.3, p.237, nota 20,1985. Habermas avalia essa citação como uma prova de que em $A$ Theory of Justice Rawls teria justamente tentado unir os empreendimentos de Kant e Hobbes e como uma prova de que ele considerou isso errado (HABERMAS, J. Justification and Application: Remarks on Discourse Ethics. [Transl. Ciaran Cronin: Erläuterungen zur Diskursethik). Cambridge: The MIT Press, s/d [1991], p.28, com referência à nota 11 .

102 RAWLS, J. Political Liberalism. New York: Columbia University Press, 1996 [1993], p.53, nota 7.

${ }^{103}$ RAWLS, J. "Justice as Fairness: Political not Metaphysical". In: Philosophy and Public Affairs. v.14, n.3, p.237, nota 20, 1985.

104 "I believe that Rawls could avoid the difficulties associated with the design of an original position if he operationalized the moral point of view in a different way, namely, if he kept the procedural conception of practical reason free of substantive connotations by developing it in a strictly procedural manner." (HABERMAS, J. The Inclusion of the Other: Studies in Political Theory. [Transl. Ciaran Cronin: Die Einbeziehung desanderen Studien zur politischen Theorie). Cambridge: MIT Press, 1998 [1996], p.57).

105 HABERMAS, J. The Inclusion of the Other: Studies in Political Theory. [Transl. Ciaran Cronin: Die Einbeziehung desanderen Studien zur politischen Theorie). Cambridge: MIT Press, 1998 [1996], p.59. 106 Idem, ibidem, p.73. 
O construtivismo sustenta que a substância moral não se funda em uma ordem independente de valores, mas se alicerça em procedimentos: "they are the product of an appropriately designed decision procedure."107 Ou seja, "that substance is best understood as constructed by free and equal people under fair conditions" 108 .

A outra interpretação possível sustenta que Kant seria um intuicionista racional ou mesmo um realista moral disfarçado ${ }^{109}$. O comentador em apreço, Kaufman, cita um texto de O’Neil, segundo o qual: "Some have thought that Kant, despite his disavowals, peddles one more form of rational intuitionism and is a covert moral realist; others, that he offers only a minimal formalism" "110. Sabidamente, a interpretação de O'Neil sustenta que a teoria kantiana, em razão de seu antirrealismo, "is more radically constructive than the one that Rawls proposes"111.

Tudo isso iria muito bem se Rawls não fosse justamente um dos responsáveis pela formulação e disseminação, no mundo anglo-americano, da interpretação construtivista de Kant, em oposição a um modelo continental justamente mais intuicionista:

This constructivist interpretation of Kant's moral thought has had a decisive influence on Kant scholarship in the Anglo-American tradition. Although many scholars in the continental tradition continue to view Kant as a rational intuitionist, [...] Kant is firmly established among Anglo-American commentators as an anti-realist and even a formalist moral thinker ${ }^{112}$.

Desse modo, com suas afirmações registradas acima, Rawls parece ter feito uma virada intuicionista. Deveras, o intuicionismo não é ausente de sua teoria. Há quem considere o capítulo II de $A$ Theory of Justice como sendo intuicionista e o cap. III como sendo construtivista: "In chapter 2, Rawls develops an intuitive argument for the principles that makes no use of the idea of the original position and argues directly from substantive considered judgements of justice. [...] the argument developed in chapter 2 is explicitly not a constructivist argument"113. Ou seja, haveria como que uma mistura de

107 KAUFMAN, A. Rawls and Kantian Constructivism. Kantian Review. v.17, Issue 02, p.227, 2012.

108 Idem, ibidem, p.228.

109 Idem, ibidem, p.228.

110 O'NEILL, O. Constructivism in Rawls and Kant. In FREEMAN, SAMUEL (Ed.). The Cambridge Companion to Rawls. Cambridge: Cambridge University Press, 2003, p.354.

111 O'NEILL, O. Constructivism in Rawls and Kant. In FREEMAN, SAMUEL (Ed.). The Cambridge Companion to Rawls. Cambridge: Cambridge University Press, 2003, p.354. Ver também FORMOSA, Paul. "Is Kant a Moral Constructivist or a Moral Realist?". In: European Journal of Philosophy, p.1-27, 2011.

112 KAUFMAN, A. "Rawls and Kantian Constructivism". In: Kantian Review. v.17, Issue 02, p.228, 2012.

113 Idem, ibidem, p.240. 
elementos intuicionistas e construtivistas: "The philosopher arrives at the basic concept of the moral person and the adjunct concepts of the politically autonomous citizen, of fair cooperation, of the well-ordered society, and so forth, via a rational reconstruction of proven intuitions, that is, intuitions actually found in the practices and traditions of a democratic society" 114 . É o próprio Rawls quem afirma que o conceito de pessoa é intuitivo: "Now the conception of persons as having the two moral powers, and therefore as free and equal, is also a basic intuitive idea assumed to be implicit in the public culture of a democratic society" 115 .

Nesse diapasão, Dworkin, baseado na afirmação de Rawls de que a posição original é puramente hipotética ${ }^{116}$, sugere ser ela um ponto intermediário de uma teoria mais profunda (deeper theory) ${ }^{117}$, cujos outros pontos seriam o equilíbrio reflexivo e o contrato social. O elemento profundo da teoria seria "[...] a right to equal concern and respect"118. De se esclarecer que o direito ao igual respeito e consideração encontra a sua base na dignidade humana ${ }^{119}$ e que o direito fundamental do qual se trata, em última análise, não é a liberdade, mas a igualdade ${ }^{120}$. Ora, essa interpretação sugere uma proximidade com aquela de Habermas, segundo a qual operariam na teoria de Rawls determinações mais profundas do que o construtivismo. Determinações de caráter substantivo. A tese de Dworkin aponta para uma convicção de Habermas no sentido de que a teoria de Rawls teria avançado em direção a fundamentos mais profundos do que os aparentemente declinados, mormente em relação ao conceito de pessoa. Como afirmado acima, tais elementos não decorreriam do contrato, mas seriam prévios a ele, devendo os mesmos serem assumidos pelo contrato ${ }^{121}$. Seria essa suposição que fundamentaria o véu de ignorância. Quem não conhecesse a sua classe social não favoreceria nenhuma

114 HABERMAS, J. The Inclusion of the Other: Studies in Political Theory. [Transl. Ciaran Cronin: Die Einbeziehung desanderen Studien zur politischen Theorie). Cambridge: MIT Press, 1998 [1996], p.60. "Reflective equilibrium is achieved at the moment when the philosopher has attained the assurance that those involved can $\mathrm{n}$ o longer reject with good reasons intuitions reconstructed and clarified in this manner." (id. Ib.).

115 RAWLS, J. "Justice as Fairness: Political not Metaphysical". In: Philosophy and Public Affairs. v.14, n.3, p.234, 1985.

${ }_{116}$ RAWLS, J. A Theory of Justice. (Revised Edition). Oxford: Oxford University Press, 1999 [1971], p.19, $\S 5$.

117 DWORKIN, R. Taking Rights Seriously. London: Duckworth, 1977, p.158.

118 Idem, ibidem, p.180, também p.182.

119 DWORKIN, R. Justice for Hedgehogs. Cambridge: Harvard University Press, 2011, p.14. 0 fundamento da dignidade se encontra no fato da consciência: "we might think that the fact of our consciousness itself, together with the phenomenal challenge of lives to lead, itself gives us all the dignity we need or should crave." (id. ib., p.230).

120 DWORKIN, R. Taking Rights Seriously. London: Duckworth, 1977, p.182.

121 Idem, ibidem, p.181. 
classe, da mesma forma quem não conhecesse a sua concepção de bem não favoreceria nenhuma forma de vida ${ }^{122}$. Ora, tais escolhas são um modo de concretizar o princípio da igualdade.

Teria, então, Rawls sucumbido à tese de que aquelas determinações substantivas da razoabilidade que compõem o véu de ignorância só poderiam ser justificadas por intuição? Nesse caso, como fica a sua crítica ao intuicionismo no $\$ 7$ de $A$ Theory of Justice de que ele seria um pluralismo de princípios, sem ordem de prioridade, fornecendo diretivas contrárias em casos particulares?

Seja como for, de acordo com Habermas, Rawls, mesmo depois de sua revisão, não nega que a posição original possa operacionalizar o ponto de vista moral, desde que pressupostas as condições do véu de ignorância: "Yet even after the revision of the initial goal that the original position was designed to achieve, he has held to the view that the meaning of the moral point of view can be operationalized in this way" 123 . Na verdade, parece ser mais do que isso, pois o raciocínio de Rawls ainda sugere operar a partir do racional, haja vista a razão que ele oferta para as partes escolherem os princípios de justiça ser a proteção de um escopo amplo de concepções de bem, sendo que os princípios de justiça seriam como que meios para tal finalidade. Ora, tal finalidade remete à racionalidade da pessoa, não à sua razoabilidade ${ }^{124}$. A explicação que Rawls parece ofertar a esse respeito é a seguinte: "it (the conception of the person) enters through the constraints of the Reasonable imposed on the parties in the original position as well as in the revised account of primary goods"125. Sendo a concepção de pessoa já incorporada nas condições da posição original, o raciocínio pode, então, ser tão somente racional: "[...] there the deliberations of the parties were rational and based on the determinate good of the persons represented"126.

A primeira objeção que Habermas faz é se, mesmo com todas essas considerações sobre o conceito de pessoa, ainda assim, o ponto de vista moral

\footnotetext{
122 Idem, ibidem, p.181.

123 HABERMAS, J. The Inclusion of the Other: Studies in Political Theory. [Transl. Ciaran Cronin: Die Einbeziehung desanderen Studien zur politischen Theorie). Cambridge: MIT Press, 1998 [1996], p.52. 124 "For the reasons we have just surveyed, the parties favor principles which protect a wide range of determinate (but unknown) conceptions of the good and which best secure the political and social conditions necessary for the adequate development and the full and informed exercise of the two moral powers. On the assumption that the basic liberties and their priority secure these conditions (under reasonably favorable circumstances), the two principles of justice, with the first principle prior to the second, are the principles agreed to." (RAWLS, J. "Justice as Fairness: Political not Metaphysical". In: Philosophy and Public Affairs. v.14, n.3, p.39, 1985).

${ }_{125}$ RAWLS, J. The Basic Liberties and Their Priority. The Tanner Lectures on Human Values. 1981, p. 86. 126 Idem, ibidem, p.86.
} 
poderia ser operacionalizado pela posição original. Ele quer saber se "the meaning of the moral point of view can be operationalized in this way"127. Ou seja, "Can the parties in the original position comprehend the highest-order interests of their clients solely on the basis of rational egoism?"128 Nesse ponto, ele endereça a Rawls as mesmas críticas que ele endereçara a Hobbes ${ }^{129}$, qual seja, uma insuficiência cognitiva nos dispositivos da posição original para representar o ponto de vista moral que deveria atender aos interesses de todos:

But if, despite this, the parties are to understand the meaning of the deontological principles they are seeking $[\ldots]$ they must be equipped with cognitive competences that extend further than the capacities sufficient for rationally choosing actors who are blind to issues of justice ${ }^{130}$.

Para se vislumbrar a dimensão do problema envolvido, há que se ter presente que um produto moral é o resultado de um argumento moral, ao passo que o interesse de um indivíduo é algo dado pelo seu desejo, logo, "the cognitive content of normative statements cannot be explained in terms of instrumental rationality" "131. É essa a razão pela qual Rawls teria que equipar as partes na posição original com um senso de justiça e não só com a racionalidade que calcula vantagens. Ora, o senso de justiça parece desempenhar um papel importante na determinação do caráter recíproco dos princípios de justiça. Se é assim, alega Habermas,

\begin{abstract}
the design loses its point by becoming too far removed from the original model. For as soon as the parties step outside the boundaries of their rational egoism and assume even a distant likeness to moral persons, the division of labor between the rationality of choice of subjects a $\mathrm{n} \mathrm{d}$ appropriate objective constraints is destroyed, a division through which self-interested agents are nonetheless supposed to arrive at morally sound decisions ${ }^{132}$.
\end{abstract}

A segunda objeção que ele faz é com relação ao conceito de direitos, o seja, "Can basic rights be assimilated to primary goods?"133. Aliás, o próprio Rawls endereçara uma crítica semelhante a Hobbes, como visto acima. Não é sem ironia que agora Habermas lhe dirija a mesma crítica. Deveras, Habermas não só concorda com a tese do déficit obrigacional do contratualismo, como

127 HABERMAS, J. The Inclusion of the Other: Studies in Political Theory. [Transl. Ciaran Cronin: Die Einbeziehung desanderen Studien zur politischen Theorie). Cambridge: MIT Press, 1998 [1996], p.52. 128 Idem, ibidem, p.52.

129 HABERMAS, J. Faktizität und Geltung: Beiträge zur Diskurstheorie des Rechts und des demokratischen Rechtsstaats. 4. Auflage, Frankfurt am Main: Suhrkamp, 1994 [1992], cap. 3. 130 HABERMAS, J. The Inclusion of the Other: Studies in Political Theory. [Transl. Ciaran Cronin: Die Einbeziehung desanderen Studien zur politischen Theorie). Cambridge: MIT Press, 1998 [1996], p.53. 131 HABERMAS, J. The Inclusion of the Other: Studies in Political Theory. [Transl. Ciaran Cronin: Die Einbeziehung desanderen Studien zur politischen Theorie). Cambridge: MIT Press, 1998 [1996], p.80. 132 Idem, ibidem, p.53-54.

${ }_{133}$ /dem, ibidem, p.52. 
se pode ver logo a seguir na sua citação com relação ao free-rider, como imputaa ao próprio Rawls, devido ao vínculo do conteúdo com a racionalidade estratégica da posição original. Segundo ele, os homens tais quais concebidos por Hobbes só podem fazer seus acordos exclusivamente sob o fundamento do que é vantajoso, haja vista não estarem equipados com a liberdade da vontade. Por isso, as suas razões permanecem atadas aos interesses e preferências contingentes ${ }^{134}$ :

The contracting parties need only consider whether it is advantageous or rational for them in light of their desires and preferences to adopt a rule of action or a system of such rules. But it is well known that this strategy misses the specific obligatory force of binding norms and valid moral statements, as is shown by the problem of the free-rider ${ }^{135}$.

Ora, isso parece muito proximo da crítica que o próprio Rawls fizera ao argumento do louco nas Lectures.

Nesse diapasão, Habermas opera uma distinção entre direitos e bens. Segundo Habermas, bens seriam preferências, já direitos decorreriam de normas que "impose equal and exceptionless obligations"136. Tais normas que estabelecem direitos teriam uma validade binária, ou seja, não caberia ponderação como ocorreria entre bens, de tal forma que uns poderiam ser mais importantes que outros. Essa determinação pressupõe uma distinção deontológica entre os direitos e o bem que contradiz a consideração inicial de que direitos também seriam bens primários ${ }^{137}$, ou seja, a equiparação de direitos a bens não daria conta do conceito de direitos, por exemplo, entendidos como trunfos, como defendido por Dworkin ${ }^{138}$, ou não daria conta do conceito de inviolabilidade da pessoa defendida pelo próprio Rawls:

Thus to respect persons is to recognize that they possess an inviolability founded on justice that even the welfare of society as a whole cannot override. It is to affirm that the loss of freedom for some is not made right by a greater welfare enjoyed by others. The lexical priorities of justice represent the value of persons that Kant says is beyond all price. The theory of justice provides a rendering of these ideas $[\ldots]^{139}$.

134 HABERMAS, J. Justification and Application: Remarks on Discourse Ethics. [Transl. Ciaran Cronin: Erläuterungen zur Diskursethik). Cambridge: The MIT Press, s/d [1991], p.27.

135 HABERMAS, J. The Inclusion of the Other: Studies in Political Theory. [Transl. Ciaran Cronin: Die Einbeziehung desanderen Studien zur politischen Theorie). Cambridge: MIT Press, 1998 [1996], p.80.

136 Idem, ibidem, p.55.

${ }^{137}$ Idem, ibidem, p.56.

138 Idem, ibidem, p. 57. Sobre o conceito de direitos como trunfos, ver DWORKIN, R. Taking Rights Seriously. London: Duckworth, 1977.

139 RAWLS, J. A Theory of Justice. (Revised Edition). Oxford: Oxford University Press, 1999 [1971], p. $513, \S 87$. 
Ora, Rawls, ao equiparar tudo a bens primários, incluso direitos, alega Habermas, faz uma espécie de nivelamento da dimensão deontológica, "leveling of the deontological dimension"140, determinando que ele tenha que compensar tal nivelamento pelo conceito de prioridade do justo sobre o bem. Rawls tem que sustentar essa prioridade para bem muscular a sua tese de uma inviolabilidade da pessoa. Com efeito, esse é o ponto mais sensível do empreendimento de Rawls, haja vista o caráter antiutilitarista de sua teoria. Ou seja, é difícil justificar uma tal prioridade a partir do cálculo interessado da pessoa que contrata: "is, however, difficult to justify from the first person perspective in which we orient ourselves to our own interests or values. H. L. A. Hart has developed this point clearly in his critique of Rawls"141. Como bem vislumbrou Hart, sob o ponto de vista contractual, só podem ser negociados bens: "For rationally choosing actors bound to the first person perspective, normative issues of whatever kind can be represented solely in terms of interests or values that are satisfied by goods" 142 .

Segundo Rawls, uma das falhas apontadas por Hart foi justamente no fundamento da prioridade do justo sobre o bem: "The first gap is that the grounds upon which the parties in the original position adopt the basic liberties and agree to their priority are not sufficiently explained"143. Veja-se a argumentação de Hart a esse respeito.

Hart mostra a dificuldade de estabelecer a prioridade do justo sobre o bem com base nos interesses racionais de cada um, pois, para que tal finalidade fosse alcançada, o argumento de Rawls teria que poder sustentar que a proibição de alguém praticar a sua religião seria pior do que a proibição para uma pessoa pobre ganhar uma vantagem econômica pela renúncia da sua liberdade religiosa, que para ela, no caso específico, significa pouco ou nada ${ }^{144}$. Como se trata de evitar o pior, neste caso, entre a proibição da prática religiosa e a proibição de negociar a liberdade religiosa por vantagem econômica, o pior seria a proibição da prática religiosa, mesmo para uma pessoa pobre que não se importa em nada com a religião. Ou seja, deveria ser melhor ter liberdade religiosa do que poder trocar a liberdade religiosa por benefícios econômicos. Segundo Hart, a defesa da prioridade poderia ser feita com base em um ideal

140 HABERMAS, J. The Inclusion of the Other: Studies in Political Theory. [Transl. Ciaran Cronin: Die Einbeziehung desanderen Studien zur politischen Theorie). Cambridge: MIT Press, 1998 [1996], p.55. 141 HABERMAS, J. The Inclusion of the Other: Studies in Political Theory. [Transl. Ciaran Cronin: Die Einbeziehung desanderen Studien zur politischen Theorie). Cambridge: MIT Press, 1998 [1996], p.56. 142 Idem, ibidem, p.54.

143 RAWLS, J. The Basic Liberties and Their Priority. The Tanner Lectures on Human Values. 1981, p.4. 144 HART, H. L. A. Rawls on Liberty and its Priority. In: DANIELS, N. (ed.). Reading Rawls: Critical Studies on Rawls' "A Theory of Justice”. Stanford: Stanford University Press, 1989 [1973], p.252. 
liberal que considerasse a atividade política um bem supremo que não poderia ser trocado por bens materiais ou por contentamento. Porém, ajunta ele, o argumento de Rawls não se baseia em ideais, mas em interesses. Com isso, Rawls teria que poder demonstrar que a prioridade da liberdade é uma preferência que toda pessoa portadora de interesses deveria ter ${ }^{145}$.

Para suprir essa falha foi necessário destacar o papel e a importância do conceito de pessoa na sua argumentação: "To fill this gap I shall introduce a certain conception of the person together with a companion conception of social cooperation"146. Sem isso, não haveria como responder a Hart. Segundo Habermas, em resposta a Hart, Rawls teve justamente que operar uma "qualification into the primary goods which secures them a relation to basic liberties as basic rights"147. O próprio Rawls explica como o conceito de pessoa passa a funcionar na teoria revisada:

A second serious weakness of the original edition was its account of primary goods. These were said to be things that rational persons want whatever else they want, [...] Primary goods are now characterized as what persons need in their status as free and equal citizens, and as normal and fully cooperating members of society over a complete life ${ }^{148}$.

Com isso, volta-se ao ponto inicial da argumentação de Habermas, qual seja, a existência velada de princípios substantivos que exorbitam do construtivismo rawlsiano ou de seu processualismo e tangenciam predicados intuicionistas que funcionariam como um deus ex machina para justificar as falhas que a teoria contratual apresentaria.

Por fim, Habermas contesta que o véu de ignorância possa garantir a imparcialidade: "Rawls imposes a common perspective on the parties in the original position through informational constraints and thereby neutralizes the multiplicity of particular interpretive perspectives from the outset"149. Nesse sentido, ele analisa a regra e ouro que já Hobbes sustentara ser a suma da lei natural. Ele critica o que chama de um teste de universalidade egocentricamente concebido, o qual não implica de modo algum que a máxima

\footnotetext{
145 HART, H. L. A. Rawls on Liberty and its Priority. In DANIELS, N. (ed.). Reading Rawls: Critical Studies on Rawls' "A Theory of Justice". Stanford: Stanford University Press, 1989 [1973], p.252.

${ }^{146}$ RAWLS, J. The Basic Liberties and Their Priority. The Tanner Lectures on Human Values. 1981, p.13. 147 HART, H. L. A. Rawls on Liberty and its Priority. In DANIELS, Norman (ed.). Reading Rawls: Critical Studies on Rawls' "A Theory of Justice”. Stanford: Stanford University Press, 1989, p.230-252.

148 RAWLS, J. A Theory of Justice. (Revised Edition). Oxford: Oxford University Press, 1999 [1971], p.XIII.

149 HABERMAS, J. The Inclusion of the Other: Studies in Political Theory. [Transl. Ciaran Cronin: Die Einbeziehung desanderen Studien zur politischen Theorie). Cambridge: MIT Press, 1998 [1996], p.57.
} 
por ele testada possa ser aceita por todos ${ }^{150}$, haja vista operar a partir do solipsismo da perspectiva individual. Para que ocorresse essa possibilidade de operar o ponto de vista de todos, a partir do ponto de vista do individual, a perspectiva do eu deveria necessariamente ser coerente com a de todos. Porém, para tal ocorrer, a identidade do eu e o seu projeto de vida deveriam refletir uma forma de vida universalmente válida que teria a capacidade de fazer com que a perspectiva do eu fosse igualmente a perspectiva de todos e, portanto, fosse boa para todos e fosse no interesse de todos ${ }^{151}$. Ora, Habermas nega que isso possa acontecer, devido ao solipsismo da consciência:

Nessa perspectiva, também o Imperativo Categórico precisa de reformulação no
sentido proposto. "For only when the self-understanding of each individual
reflects a transcendental consciousness, that is, a universally valid view of the
world, would what from my point of view is equally good for all actually be in
the equal interest of each individual. But this can no longer be assumed under
conditions of social and ideological pluralism" ${ }^{152}$.

Por isso é que ele propôs uma reformulação do próprio imperativo categórico: "the role of the categorical imperative is taken over by an intersubjectively applied procedure" 153 Segundo ele,

Kant's categorical imperative already goes beyond the egocentric character of
the Golden Rule: 'Do not do unto others what you would not have them do
unto you.' Whereas this rule calls for a universalization test from the viewpoint
of a given individual, the categorical imperative requires that all those possibly
affected be able to will a just maxim as a general rule. But as long as we apply
this more exacting test in a monological fashion, each of us still considers
privately what all could will from individually isolated perspectives. This is
inadequate ${ }^{154}$.

Daí se entende a marca intersubjetiva que ele dá ao princípio de universalização, defendido pela ética discursiva por ele proposta: "Dei a (U) $)^{155}$ uma versão que exclui uma aplicação monológica desse princípio; (...) Como Kant, Rawls operacionaliza de tal maneira o ponto de vista da imparcialidade

150 HABERMAS, J. Justification and Application: Remarks on Discourse Ethics. [Transl. Ciaran Cronin: Erläuterungen zur Diskursethik). Cambridge: The MIT Press, s/d [1991], p.7.

151 Idem, ibidem, p.7-8.

152 HABERMAS, J. Consciência moral e agir comunicativo. [Trad. Guido A. de Almeida: Moralbewusstsein und kommunikatives Handeln). Rio de Janeiro: Tempo Brasileiro, 1989 [1983], p.88.

153 HABERMAS, J. The Inclusion of the Other: Studies in Political Theory. [Transl. Ciaran Cronin: Die Einbeziehung desanderen Studien zur politischen Theorie). Cambridge: MIT Press, 1998 [1996], p.57. 154 HABERMAS, J. The Inclusion of the Other: Studies in Political Theory. [Transl. Ciaran Cronin: Die Einbeziehung desanderen Studien zur politischen Theorie). Cambridge: MIT Press, 1998 [1996], p.57. 155 Princípio de universalização. 
que cada indivíduo possa empreender por si só a tentativa de justificar normas básicas" 156.

Em apertada síntese, Habermas imputa a Rawls uma crítica que este último fizera a Hobbes, qual seja, aquela de um déficit obrigacional nos produtos gerados pelo procedimento contratual. De outro lado, ele imputa tanto a Rawls quanto a Hobbes um déficit cognitivo em relação à possibilidade do procedimento contratual dar conta do ponto de vista de todos que é o exigido pela justiça. Assim, no caso de Hobbes, os argumentos de estirpe moral seriam sub-repticiamente operantes, via regra de ouro, a qual Hobbes diz ser a suma das leis naturais. Desse modo, alega Habermas, subrepticiamente, Hobbes introduz argumentos morais em sua teoria. Do mesmo modo, Rawls, acusa ele, também contrabandeia a moral para a sua teoria contratual, via o conceito de pessoa e via as condições do véu de ignorância, as quais ele interpreta como determinações morais substantivas concernentes à razoabilidade. Dito claramente, a razoabilidade não decorre como um produto da posição original, mas a precede. Em epítome, ele moraliza Hobbes e moraliza Rawls como solução para os seus problemas concernentes ao déficit cognitivo do contratualismo.

Resta saber se o próprio Habermas conseguirá honrar a sua dicção da neutralidade do princípio do discurso, que constitui estratégia fundamental para o seu empreendimento de uma fundamentação dos direitos básicos não dependente de argumentos morais. ${ }^{157}$ Apel é um dos que negam que isso seja possível158.

\section{Referências}

AIRAKSINEN, T.; SIITONEN, A. "Kant on Hobbes, Peace, and Obedience". In: History of European Ideas, v.30, 2004, p.315-328.

BARBOSA FILHO, B. "Condições da autoridade e autorização em Hobbes". In: Filosofia Politica 6. Porto Alegre: L\&PM, 1991, p.63-75.

BERTEN, A. "Habermas crítico de Rawls: a posição original do ponto de vista da pragmática universal”. In: BOMBASSARO, L. C.; PAVIANI, J. (orgs.). Filosofia, lógica e existência: homenagem a Antonio Carlos Kroeff Soares. Caxias do Sul: EDUCS, 1997, p.24-47.

156 HABERMAS, J. Consciência moral e agir comunicativo. [Trad. Guido A. de Almeida: Moralbewusstsein und kommunikatives Handeln). Rio de Janeiro: Tempo Brasileiro, 1989 [1983], p.87.

157 HABERMAS, J. Faktizität und Geltung: Beiträge zur Diskurstheorie des Rechts und des demokratischen Rechtsstaats. 4. Auflage, Frankfurt am Main: Suhrkamp, 1994 [1992], cap. III.

158 APEL, K.-O., OLIVEIRA, M. A. e MOREIRA, L. Com Habermas, contra Habermas: direito, discurso e democracia. São Paulo: Landy, 2004. 
. "Por que Habermas não é e não pode ser um contratualista?". In: PINZANI, A.; VOLPATO DUTRA, D. Habermas em discussão. Anais do Colóquio Habermas realizado na UFSC (Florianópolis, 30 de março - $1^{\circ}$. de Abril de 2005). Florianópolis: NÉFIPO, 2005, p.128-142.

BURGESS, G. "Hobbesian Resistance Theory”. In: Political Studies, v.42, n.1, p.6283, 1994.

CFM. Resolução CFM No. 1931/2009. (Publicada no D.O.U. de 24 de setembro de 2009, Seção I, p. 90) (Retificação publicada no D.O.U. de 13 de outubro de 2009, Seção I, p.173). Aprova o Código de Ética Médica.

CHKA, J. “Imputation”. In: Brigham Young University Law Review, p.669-710, 1986.

COHEN, G. A. Rescuing Justice and Equality. Cambridge: Harvard University Press, 2008.

CURRAN, E. “Hobbes's Theory of Rights: A Modern Interest Theory". In: The Journal of Ethics, v. 6, n.1, p.63-86, 2002.

Macmillan, 2007.

- Reclaiming the Rights of the Hobbesian Subject. Chippenham: Palgrave

DWORKIN, R. Justice for Hedgehogs. Cambridge: Harvard University Press, 2011. . Taking Rights Seriously. London: Duckworth, 1977.

EDWARD, E. C. A Brief View and Survey of the Dangerous and Pernicious Errors to Church and State in Mr. Hobbes's Book, Entitled Leviathan. Oxford: Bathurst, 1676.

FICHTE, J. G. Foundations of Natural Right According to the Principles of the Wissenschaftslebre. [Grundlage des Naturrechts nach Principien der Wissenschaftslehre: Trans.by Michael Bauer]. Cambridge: Cambridge University Press, 2000 [1796-7].

FINKELSTEIN, C. "A Puzzle about Hobbes on Self-Defense". In: Pacific Philosophical Quarterly, v.82, n.3-4, p.332-361, 2001.

FOISNEAU, L.; THOUARD, D. [ed.]. De la violence à la politique: Kant et Hobbes. Paris: Vrin, 2005.

FORMOSA, P. "Is Kant a Moral Constructivist or a Moral Realist?”. In: European Journal of Philosophy, p.1-27, 2011.

GAUTHIER, D. "Hobbes: the Laws of Nature". In: Pacific Philosophical Quarterly, v. 82, p.258-284, 2001.

. "Public Reason". In: Social Philosophy \& Policy, v. 12, p.19-42, 1994.

. The Logic of Leviathan. Oxford: Clarendon Press, 1969. 
GERT, B. "The Law of Nature as the Moral Law”. In: Hobbes Studies, v.1, p.26-44, 1988.

GREGOR, M. J. Law of Freedom: A Study of Kant's Method of Applying the Categorical Imperative in the 'Methapysik der Sitten'. Oxford: Blackwell, 1963.

HABERMAS, J. A inclusão do outro: estudos de teoria política. [Trad. G. Sperber, P. A. Soethe, M. C. Mota: Die Einbeziehung des Anderen: Studien zur politischen Theorie]. 2. ed., São Paulo: Loyola, 2004.

- Consciência moral e agir comunicativo. (Trad. Guido A. de Almeida: Moralbewusstsein und kommunikatives Handeln). Rio de Janeiro: Tempo Brasileiro, 1989.

Die Einbeziehung des Anderen: Studien zur politischen Theorie. Frankfurt am Main: Suhrkamp, 1997.

Direito e democracia: entre faticidade e validade. [v. I e II]. [Trad. F. B. Siebeneichler: Faktizität und Geltung: Beiträge zur Diskurstheorie des Rechts und des demokratischen Rechtsstaats]. Rio de Janeiro: Tempo Brasileiro, 1997.

Faktiqität und Geltung: Beiträge zur Diskurstheorie des Rechts und des demokratischen Rechtsstaats. 4. Auflage, Frankfurt am Main: Suhrkamp, 1994.

2007.

Identidades nacionales y postnacionales. [M. J. Redondo]. 3.ed., Madrid: Tecnos,

. The Inclusion of the Other: Studies in Political Theory. [Transl. Ciaran Cronin: Die Einbeziehung desanderen Studien zur politischen Theorie]. Cambridge: MIT Press, 1998 [1996].

Theory and Practice. [Translated by John Viertel: Theorie und Praxis]. Boston: Beacon Press, 1974 [1968].

HAMPTON, J. Hobbes and the Social Contract Tradition. Cambridge: Cambridge University Press, 1986.

HART, H. L .A. “Are There Any Natural Rights?”. In: The Philosophical Review, v.64, n.2, p.175-191, 1955.

HARVEY, M. "Moral Justification in Hobbes”. In: Hobbes Studies. V. XII, p.33-51, 1999.

HEDRICK, T. Rawls and Habermas: Reason, Pluralism, and the Claims of Political Philosophy. Stanford: Stanford University Press, 2010.

HEGEL, G. W. F. "On the Scientific Ways of Treating Natural Law, on its Place in Practical Philosophy, and its Relation to the Positive Sciences of Right (18021803)”. In: HEGEL, G. W. F. Political Writings. [Org. by Laurence Dickey and H. B. Nisbet. Tansl. by H. B. Nisbet]. Cambridge: Cambridge University Press, 2004, p.102-180. 
HERBERT, G. B. "Fear of Death and the Foundations of Natural Right in the Philosophy of Thomas Hobbes”. In: Hobbes Studies, v.7, p.56-68, 1994.

. “Kant Contra Hobbes”. In: Hobbes Studies, v.17, n.1, p.3-27, 2004.

HERBERT, G. B. "The Non-normative Nature of Hobbesian Natural Law". In: Hobbes Studies, v.22, p.3-28, 2009.

HOBBES, T. Leviathan: sive de materia, forma, et potestate civitatis ecclesiasticae et civilis. [Thomæ Hobbes Malmesburiensis Opera Philosophica Quæ Latine Scripsit Omnia, Volume 3, William Molesworth (ed.)]. Charleston: Nabu Press, 2010 [1668].

. A Dialogue between a Philosopher and a Student of the Common Laws of England. [English Works of Thomas Hobbes. V.6, ed. Sir William Molesworth. London: John Bohn, 1945]. Indianápolis: Liberty Fund: 2005 [1681]. [http://oll.libertyfund.org/EBooks/Hobbes_0298.pdf]. . De Cive. Oxford: Clarendon, 1983 [1642].

. Do cidadão. [R. J. Ribeiro: Philosophical Rudiments Concerning Government and Society]. 2. ed., São Paulo: Martins Fontes, 1998 [1642].

. English Works of Thomas Hobbes. [Vols. 1-10, ed. Sir William Molesworth]. London: John Bohn, 1939-1945.

. Leviatã ou matéria, forma e poder de um estado eclesiático e civil. [Trad. J. P. Monteiro e M.B.N. da Silva: Leviathan, or Matter, Form, and Power of a Commonwealth Ecclesiastical and Civil]. 2. ed., São Paulo: Abril Cultural, 1979.

. Leviathan, or Matter, Form, and Power of a Commonwealth Ecclesiastical and Civil. [Edited by C.B. Macpherson]. London: Penguin, 1968 [1651].

. The Elements of Law Natural and Politic. Cambridge: Cambridge University Press, 1928 [1640].

HODGSON, L. P. "Kant on the Right to Freedom: A Defense". In: Ethics, v.120, n.4, p.791-819, 2010.

HÖFFE, O. "'Even a Nation of Devil Needs the Satate': the Dilemma of Natural Justice”. In: WILLIAMS, Howard Lloyd [ed.]. Essays on Kant's Political Philosophy. Chicago: The University of Chicago Press, 1992, p.120-142.

- Justiça política: fundamentação de uma filosofia crítica do direito e do estado. [Ernildo Stein: Politische Gerechtigkeit]. Petrópolis: Vozes, 1991.

HÜNING, D. "Hobbes on the Right to Punish". In SPRINGBORG, Patricia [Ed.]. The Cambridge Companion to HOBBES'S LEVIATHAN. Cambridge: Cambridge University Press, 2007, p.217-242. 
HUNTER, I.; SAUNDERS, D. [Ed.]. Natural law and civil Sovereignty: moral right and state authority in early modern political thought. Chippenham: Palgrave Macmillan, 2002.

JAUME, L. "Hobbes and the Philosophical Sources of Liberalism". In: SPRINGBORG, P. [Ed.]. The Cambridge Companion to HOBBES'S LEV LATHAN. Cambridge: Cambridge University Press, 2007, p.199-216.

KANT, I. A metafísica dos costumes. [Tr. J. Lamego]. Lisboa: Fundação Calouste Gulbenkian, 2005. . A pazperpétua e outros opúsculos. (Trad. A. Morão). Lisboa: E. 70, 1988.

- Crítica da razão prática. (Trad. Valério Rohden: Kritik der praktischen Vernunft). São Paulo: Martins Fontes, 2002.

Fundamentação da metafísica dos costumes. [Trad. G. A. de Almeida: Grundlegung zur Metaphysik der Sitten]. São Paulo: Discurso Editorial/Barcarolla, 2009.

KAUFMAN, A. "Rawls and Kantian Constructivism". In: Kantian Review, v.17, Issue 02, p.227-256, 2012.

KERVÉGAN, J.-F. Hegel, Carl Schmitt: o politico entre a especulação e a positividade. [C. Huang: Hegel, Carl Schmitt - Le politique entre spéculation et positivité]. Barueri: Manole, 2006.

KRIEGEL, B. "The Rule of the State and Natural Law". In HUNTER, I.; SAUNDERS, D. [Ed.]. Natural law and civil sovereignty: moral right and state authority in early modern political thought. Chippenham: Palgrave Macmillan, 2002, p.13-26.

LIMONGI, M. I. "Direito e Poder: Hobbes e a dissolução do Estado". In: Dois Pontos, v.6, n.3, p.181-193, 2009.

LLOYD, S. "Hobbes's Self-effacing Natural Law Theory". In: Pacific Philosophical Quarterly, v.82, n.3-4, p.285-308, 2001.

LOCKE, J. Two Treaties of Government and A Letter Concerning Toleration. [Ed. by Ian Shapiro]. New Haven and London: Yale University Press, 2003 [1690 \&1689].

LOPARIC, Z. “O problema fundamental da semântica jurídica de Kant”. In: WRIGLEY, M. B.; SMITH, P. J. O filósofo e sua história: uma homenagem a Oswaldo Porchat. [Coleção CLE, v.36]. Campinas: UNICAMP, 2003, p.477-520.

MOEHLER, M. A Hobbesian Derivation of the Principle of Universalization. Philosophical Studies, v. 158, n.1, 2011, p. 83-107.

. "The (Stabilized) Nash Bargaining Solution as a Principle of Distributive Justice". In: Utilitas, v.22, p.447-473, 2010.

. "Why Hobbes' State of Nature is Best Modeled by an Assurance Game".

In: Utilitas, n.21, p.297-326, 2009. 
NAGEL, T. "Hobbes's Concept of Obligation”. In: Philosophical Review, v.68, p.68$83,1959$.

O’NEILL, O. "Constructivism in Rawls and Kant". In: FREEMAN, SAMUEL [Ed.]. The Cambridge Companion to Rawls. Cambridge: Cambridge University Press, 2003, p.347-367.

OWEN, J. J. "The Tolerant Leviathan: Hobbes and the Paradox of Liberalism". In: Polity, v.37, n.1, p.130-148, 2005.

. "The Tolerant Leviathan: Hobbes and the Paradox of Liberalism". In: Polity, v.37, n.1, p.130-148, 2005.

PAVÃO, A. "Hobbes e a moralidade: a leitura kantiana”. In: Dissertartio, n.24, p.7992, 2006.

PEACOCK, M. “Obligation and Advantage in Hobbes' Leviathan”. In: Canadian Journal of Philosophy, v.40, n.3, p.433-458, 2010.

PETTIT, P. Made with Words: Hobbes on Language, Mind, and Politics. Princeton and Oxford: Princeton University Press, 2008.

- Republicanism: A Theory of Freedom and Government. Oxford: Oxford University Press, 1997 [1982].

RAWLS, J. A Theory of Justice. [Revised Edition]. Oxford: Oxford University Press, 1999 [1971].

. "Justice as Fairness: Political not Metaphysical". In: Philosophy and Public Affairs, v.14, n.3, p.223-251, 1985.

Lectures on the History of Political Philosophy. Cambridge, MA: Harvard University Press, 2007.

. Political Liberalism. New York: Columbia University Press, 1996 [1993].

RIBEIRO, R. J. "“Men of Feminine Courage': Thomas Hobbes and Life as a Right”. In: Hobbes Studies, v.24, n.1, p.44-61, 2011.

. “Notas”. In: HOBBES, Thomas. Do cidadão. [R. J. Ribeiro: Philosophical

Rudiments Concerning Government and Society]. 2. ed., São Paulo: Martins Fontes, 1998 [1642].

SCHMITT, C. El Leviathan en la teoría del estado de Tomas Hobbes. [Trad. F. J. Conde]. Granada: Comares, 2004.

SCHOPENHAUER, A. The Basis of Morality. [Trans. A. B. Bullock]. 2. ed., London: George Allen, 1915 [1840].

SREEDHAR, S. "Defending the Hobbesian Right of Self-Defense". In: Political Theory, v.36, n.6, p.781-802, 2008. 
Press, 2010.

Hobbes on Resistance: Defying the Leviathan. Cambridge: Cambridge University

STRAUSS, L. Natural Right and History. Chicago: The University of Chicago Press, 1965 [1953].

. The Political Philosophy of Hobbes: Its Basis and Its Genesis. [Transl. by E.M. Sinclair]. Chicago: The University of Chicago Press, 1952 [1936].

TIERNEY, B. "Natural Law and Natural Rights: Old Problems and Recent Approaches". In: Review of Politics, v.64, n.3, p.390-415, 2002.

TRALAU, J. "Hobbes contra Liberty of Conscience". In: Political Theory, v.39, n.1, p.58-84, 2011.

URBINATI, N. Representative Democracy: Principles and Genealogy. Chicago: The University of Chicago Press, 2006.

VOLPATO DUTRA, D. J. "Direitos, deveres não: o teor cognitivo da moral moderna”. In: Veritas, v.56, p.108-124, 2011.

. "Grotius: pré-história da teoria kantiana da virtude". In: Dissertatio, v.33, p.439-453, 2011.

. Kant e Habermas: a reformulação discursiva da moral kantiana. Porto Alegre: EDIPUCRS, 2002.

- Razão e consenso em Habermas: a teoria discursiva da verdade, da moral, do direito e da biotecnologia. Florianópolis: Editora da UFSC, 2005.

WARRENDER, H. The Political Philosophy of Hobbes. Oxford: Oxford University Press, 1957.

WEINRIB, E. "Law as a Kantian Idea of Reason". In: Columbia Law Review, v.87, p.472, 1987.

"Legal Formalism: On the Immanent Rationality of Law". In: Yale Law Journal, v.97, p.949-999, 1987/1988.

WILLIAMS, H. Kant's Critique of Hobbes. University of Wales Press, 2003.

ZAGORIN, P. "Hobbes without Grotius". In: History of Political Thought, v.XXI, n.1, p.16-40, 2000.

ZUCKERT, M. P. "Do natural rights derive from natural law?". In: Harvard Journal of Law \& Public Policy, v.20, n.3, p.695-733, 1997.

Press, 1998.

Natural Rights and the New Republicanism. Princeton: Princeton University . "Response to Brian Tierney". In: Review of Politics, v.64, n.3, 2002. 
; ZUCHERT, C. The Truth about Leo Strauss: Political Philosophy and American Democracy. Chicago and London: The University of Chicago Press, 2006.

E-mail: djvdutra@yahoo.com.br

Recebido: $11 / 02 / 2017$

Aprovado: 05/04/2017 